\title{
End-of-test Performance and Wear Characterization of NASA's Evolutionary Xenon Thruster (NEXT) Long- Duration Test
}

\author{
Rohit Shastry ${ }^{1}$, Daniel A. Herman ${ }^{2}$, George C. Soulas ${ }^{3}$ and Michael J. Patterson ${ }^{4}$ \\ NASA Glenn Research Center, Cleveland, OH, 44135
}

\begin{abstract}
The NASA's Evolutionary Xenon Thruster (NEXT) project is developing the nextgeneration solar electric ion propulsion system with significant advancements beyond the state-of-the-art NASA Solar Electric Propulsion Technology Application Readiness (NSTAR) ion propulsion system to provide future NASA science missions with enhanced capabilities. A Long-Duration Test (LDT) was initiated in June 2005 to validate the thruster service life modeling and to quantify the thruster propellant throughput capability. Testing was recently completed in February 2014, with the thruster accumulating 51,184 hours of operation, processing $918 \mathrm{~kg}$ of xenon propellant, and delivering $35.5 \mathrm{MN}-\mathrm{s}$ of total impulse. As part of the test termination procedure, a comprehensive performance characterization was performed across the entire NEXT throttle table. This was performed prior to planned repairs of numerous diagnostics that had become inoperable over the course of the test. After completion of these diagnostic repairs in November 2013, a comprehensive end-of-test performance and wear characterization was performed on the test article prior to exposure to atmosphere. These data have confirmed steady thruster performance with minimal degradation as well as mitigation of numerous life limiting mechanisms encountered in the NSTAR design. Component erosion rates compare favorably to pretest predictions based on semi-empirical models used for the thruster service life assessment. Additional data relating to ion beam density profiles, facility backsputter rates, facility backpressure effects on thruster telemetry, and modulation of the neutralizer keeper current are presented as part of the end-of-test characterization. Presently the test article for the NEXT LDT has been vented to atmosphere with post-test disassembly and inspection underway.
\end{abstract}

\section{Nomenclature}

$\begin{array}{ll}B O L & =\text { beginning-of-life } \\ C E X & =\text { charge exchange } \\ C R A & =\text { center radius aperture } \\ D C A & =\text { discharge cathode assembly } \\ E L T & =\text { extended life test } \\ E M & =\text { engineering model } \\ E M 3 & =\text { engineering model } 3 \text { thruster } \\ E P C & =\text { end-of-test performance characterization } \\ G R C & =\text { NASA Glenn Research Center } \\ H i P E P & =\text { High-Power Electric Propulsion } \\ I P S & =\text { ion propulsion system } \\ J_{B} & =\text { beam current, A } \\ J_{N K} & =\text { neutralizer keeper current, A } \\ L D T & =\text { long-duration test } \\ \dot{m}_{M} & =\text { main plenum mass flow rate, sccm } \\ \dot{m}_{C} & =\text { discharge cathode mass flow rate, } \mathrm{sccm}\end{array}$

\footnotetext{
${ }^{1}$ Aerospace Engineer, In-Space Propulsion Systems Branch, 21000 Brookpark Rd, MS 301-3, AIAA member.

${ }^{2}$ Aerospace Engineer, In-Space Propulsion Systems Branch, 21000 Brookpark Rd, MS 86-8, AIAA senior member.

${ }^{3}$ Aerospace Engineer, In-Space Propulsion Systems Branch, 21000 Brookpark Rd, MS 16-1, AIAA member.

${ }^{4}$ Senior Technologist, Propulsion Division, 21000 Brookpark Rd, MS 301-3, AIAA member.
} 


$\begin{array}{ll}\dot{m}_{N} & =\text { neutralizer cathode mass flow rate, sccm } \\ N C A & =\text { neutralizer cathode assembly } \\ N E X T & =\text { NASA's Evolutionary Xenon Thruster } \\ N S T A R & =\text { NASA's Solar Electric Propulsion Technology Application Readiness } \\ P_{I N} & =\text { input power, } \mathrm{kW} \\ P M & =\text { prototype model } \\ P P C & =\text { post-test performance characterization } \\ P P U & =\text { power processing unit } \\ Q C M & =\text { quartz-crystal microbalance } \\ T L & =\text { throttle level } \\ T T 9 & =\text { Throttle Table } 9 \\ T T 10 & =\text { Throttle Table } 10 \\ V_{A} & =\text { accelerator grid voltage, } \mathrm{V} \\ V_{B} & =\text { beam power supply voltage, } \mathrm{V} \\ V F & =\text { vacuum facility } \\ W T & =\text { wear test } \\ \varphi & =\text { aperture or orifice diameter }\end{array}$

\section{Introduction}

$\mathrm{N}$ ASA has identified the need for a higher-power, higher-specific impulse, higher-thrust, and higher-throughput capable ion propulsion system (IPS) beyond the state-of-the-art NASA Solar Electric Propulsion Technology Application Readiness (NSTAR) IPS employed on the Deep Space 1 and Dawn Missions. ${ }^{1-4}$ To fill this need, the NASA's Evolutionary Xenon Thruster (NEXT) IPS development, led by the NASA Glenn Research Center (GRC), was competitively selected in 2002. The NEXT IPS advanced technology development has been performed under the sponsorship of NASA's In-Space Propulsion Technology Program. The highest fidelity NEXT hardware planned was built by the government/industry NEXT team and includes: an engineering model (referred to as a prototype model) thruster, an engineering model power processing unit (PPU), engineering model propellant management assemblies, a prototype gimbal, and control unit simulators. ${ }^{5}$ Each of these units underwent extensive component level testing, completed environmental testing (with the exception of the PPU), and was tested together in system integration testing. ${ }^{6-9}$ The status of the NEXT project, results from IPS component testing, and the results of integration testing can be found in Refs. 5-15.

The NEXT thruster service life capability is being assessed through a comprehensive service life validation scheme that utilizes a combination of testing and analyses. This methodology is consistent with the lifetime qualification approach recommended in open literature for electric thrusters. ${ }^{16}$ Since the NEXT thruster is an evolution of the NSTAR thruster design, the understanding of plasma physics and erosion processes gained from NSTAR's development project applies to the NEXT thruster. The NEXT thruster, as a second-generation deepspace ion thruster, made use of over 70,000 hours of ground and flight test experience (not including the accumulated hours from the NSTAR IPS on the ongoing Dawn mission) in both the design of the NEXT thruster and evaluation of thruster wear-out failure modes. A NEXT service life assessment was conducted at NASA GRC, employing several models to evaluate all known failure modes with high confidence based upon the substantial amount of ion thruster testing dating back to the early 1960s. ${ }^{17,} 18$ The NEXT service life assessment also incorporated results from the NEXT 2,000 h wear test conducted on a NEXT laboratory model (referred to as engineering model) thruster operating at full power $(6.9 \mathrm{~kW}) .{ }^{17,19}$ The transparency between the laboratory model (referred to engineering model) and engineering model (referred to as prototype model) thruster wear characteristics was demonstrated by a short-duration prototype model wear test. ${ }^{20,21}$ The references for the NEXT service life assessment explain the thruster performance and erosion modeling analyses. ${ }^{17,18}$

The NEXT Long-Duration Test (LDT) was initiated in June 2005 to validate the NEXT thruster service life model as well as quantify the NEXT thruster lifetime. The goals of the NEXT LDT were to demonstrate the initial project qualification propellant throughput requirement of $450 \mathrm{~kg}$, validate thruster service life model's predictions, quantify thruster performance and erosion as a function of thruster wear and throttle level, and identify any unknown life-limiting mechanisms. In December 2009, after successfully demonstrating the original qualification throughput requirement of $450 \mathrm{~kg}$, the first listed goal was redefined to test to failure of the thruster or until decision to terminate the test voluntarily. 


\section{NEXT Long-Duration Test Background and Status}

The NEXT LDT was conducted within Vacuum Facility 16 (VF16) at NASA GRC. The test article is a modified version of an engineering model (designated EM3), shown firing in Fig. 1. To obtain a flight-representative configuration, prototype-model (PM) ion optics were incorporated, provided by industry partner Aerojet Corporation. A graphite discharge cathode keeper electrode was also incorporated into EM3. ${ }^{22}$ The NEXT thruster is nominally a 0.5-6.9 $\mathrm{kW}$ input power xenon thruster utilizing 2-grid dished-out ion optics, capable of producing thrust values from $25-237 \mathrm{mN}$ and specific impulses from 1300-4150 seconds. The technical approach for the NEXT design continues the derating philosophy used for the NSTAR ion thruster. A beam extraction area 1.6 times that of NSTAR allows for higher thruster input power while maintaining low discharge voltages and ion current densities, thus maintaining thruster longevity. Additional descriptions of the hardware, including the NEXT EM3 design and vacuum facility, can be found in Refs. 2, 20, and 23-27.

Various diagnostics were utilized to characterize the performance

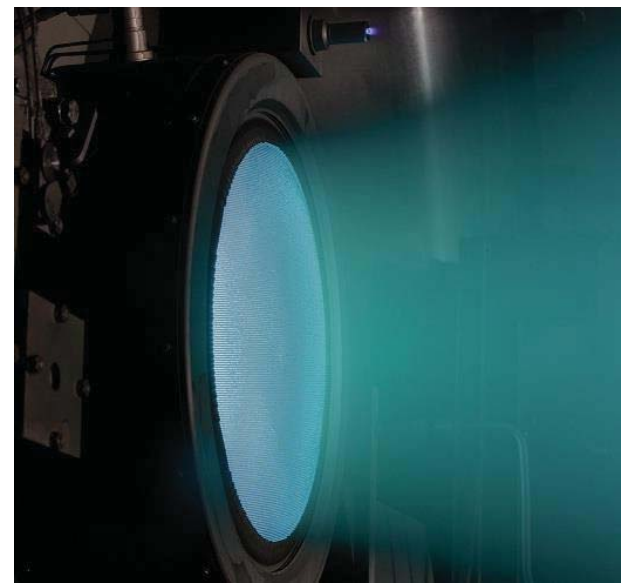

Figure 1. NEXT EM3 firing within VF-16 at full power during the Long-Duration Test. and wear of the thruster during the LDT. These include: three staggered planar probes on a single-axis motion table to monitor ion current density distributions and beam divergence, a quartz-crystal microbalance (QCM) to monitor backsputtered efflux from the facility, and an $\mathrm{E} \times \mathrm{B}$ probe to monitor the charge-state signature of the thruster plume. There is also a data acquisition and control system that monitored the thruster telemetry at $15 \mathrm{~Hz}$ and permitted autonomous operation. A set of six in-situ, charge-coupled device cameras were placed on the single-axis motion table to monitor critical component wear rates on the thruster. These cameras imaged the downstream neutralizer keeper and cathode orifice plates, the discharge keeper and cathode orifice plates, accelerator grid apertures at various radial locations from centerline, and the cold grid gap of the ion optics. Additional details of the testing and facility diagnostics can be found in Refs. 25 and 28.

The NEXT IPS was designed for solar electric propulsion applications that experience variable input power as the available solar flux changes with distance from the sun throughout the mission. To accommodate this variation in available power the NEXT thruster is capable of throttling from 0.5-6.9 $\mathrm{kW}$ input power. The EM3 thruster was operated in a mission-representative profile comprised of discrete segments at various power levels shown in Table 1 and described in detail in Ref. 29. The thruster was operated at each of these segments for sufficient duration to characterize the performance and wear rates and to validate the thruster service life models. The original qualification throughput of $450 \mathrm{~kg}$ was achieved in December 2009. ${ }^{30}$ The throttle profile was completed in May 2010 and the thruster was operated at full power since that time. For the majority of the test, detailed performance characterizations were carried out at 11 of the 40 operating conditions in the NEXT throttle table. These characterizations included overall thruster performance as well as component performance of the discharge chamber, neutralizer cathode, and ion optics. Details of the NEXT Throttle Table 10 (TT10) can be found in Ref. 31 .

Table 1. NEXT Long-Duration Test mission-representative throttling profile. Since throttling profile completion, the thruster was operated at full input power (TL40).

\begin{tabular}{|c|c|c|c|c|c|}
\hline $\begin{array}{c}\text { Throttle } \\
\text { Segment }\end{array}$ & $\begin{array}{c}\text { Throttle } \\
\text { Level }\end{array}$ & $\begin{array}{c}\text { Input Power, } \\
\mathrm{kW}\end{array}$ & $\begin{array}{c}\text { Operating Condition } \\
\left(\mathrm{J}_{\mathrm{B}}, \mathrm{V}_{\mathrm{B}}\right)\end{array}$ & $\begin{array}{c}\text { Segment Duration, } \\
\mathrm{kh}\end{array}$ & $\begin{array}{c}\text { End of Segment } \\
\text { Date }\end{array}$ \\
\hline \hline 1 & TL40 & 6.9 & $3.52 \mathrm{~A}, 1800 \mathrm{~V}$ & 13.0 & $11 / 17 / 2007$ \\
\hline 2 & TL37 & 4.7 & $3.52 \mathrm{~A}, 1179 \mathrm{~V}$ & 6.5 & $12 / 23 / 2008$ \\
\hline 3 & TL05 & 1.1 & $1.20 \mathrm{~A}, 679 \mathrm{~V}$ & 3.4 & $06 / 24 / 2009$ \\
\hline 4 & TL01 & 0.5 & $1.00 \mathrm{~A}, 275 \mathrm{~V}$ & 3.2 & $12 / 15 / 2009$ \\
\hline 5 & TL12 & 2.4 & $1.20 \mathrm{~A}, 1800 \mathrm{~V}$ & 3.1 & $05 / 05 / 2010$ \\
\hline 6 & TL40 & 6.9 & $3.52 \mathrm{~A}, 1800 \mathrm{~V}$ & 21.9 & $02 / 28 / 2014$ \\
\hline
\end{tabular}

A decision to voluntarily terminate the LDT was made in April 2013 due to budgetary constraints. Since then, a comprehensive post-test performance characterization (PPC) was conducted across all 40 operating conditions of the throttle table. However, this PPC did not include certain data such as ion current density and facility backsputter 
measurements due to diagnostic failures that occurred earlier in the test. Since these data were necessary to characterize the state of the thruster at end-of-test, the LDT termination procedure included plans to repair all failed diagnostics while keeping the thruster under hard vacuum. Prior to the initiation of the LDT, EM3 was placed on a push-pull rod system which allowed the thruster to be retracted into the VF-16 port and isolated while the main chamber is vented to atmospheric conditions. The facility port is equipped with its own cryopump to maintain hard vacuum while the main facility is vented. Due to the inherent risk of the retraction/extension motion to the thruster hardware, the PPC was executed prior to the diagnostic repair in the event that the thruster became inoperable during the retraction and repair process. Details of the comprehensive PPC can be found in Ref. 32.

The diagnostic repairs were successfully completed in November 2013. Just prior to venting the facility, an abbreviated performance characterization was conducted to compare the state of the thruster before and after the diagnostic repair to ensure no significant changes occurred as a result of the retraction/extension process. Details of the diagnostic repair itself can be found in Section III. Following extension of the thruster back into the main chamber volume, a comprehensive end-of-test performance characterization (EPC) was performed which duplicated all the performance measurements from the PPC while including measurements from all the repaired diagnostics. The results of the EPC are the focus of this paper.

Data collection for the LDT was completed in February 2014. At the time of completion, the thruster had accumulated 51,184 hours of high-voltage operation, processed $918 \mathrm{~kg}$ of propellant, and delivered $35.5 \mathrm{MN}-\mathrm{s}$ of total impulse. The NEXT LDT has demonstrated a significant improvement in thruster lifetime compared to the existing state-of-the-art NSTAR thruster, and has set numerous records for the most demonstrated lifetime of an electric propulsion device, including most hours of operation, highest propellant throughput, greatest total impulse, and longest hollow cathode operation. Since NEXT has demonstrated far more propellant throughput capability than the original $450 \mathrm{~kg}$ qualification requirement, additional missions with even greater lifetime requirements are enabled by NEXT. Furthermore, missions whose analyses employed multiple thruster strings to meet lifetime requirements can be simplified, reducing cost and complexity of the propulsion system.

In April 2014, EM3 was successfully exposed to atmosphere for the first time in nearly nine years and moved to a clean room for post-test inspections. Thruster disassembly and inspection is presently underway. While certain findings from the post-test inspection are briefly mentioned here, a detailed discussion of such results is beyond the scope of this paper and will be reported in a future publication.

\section{Diagnostics Repair Summary}

The diagnostic repairs within VF-16 occurred over a 2-3 week period in November 2013. At the time of the repair, the thruster had accumulated 50,453 hours of high-voltage operation, processed $907 \mathrm{~kg}$ of propellant, and delivered 35.1 MN-s of total impulse. The process included the following steps:

- retraction of the thruster into the VF-16 port and subsequent isolation from the main chamber

- slow vent of the main chamber to atmospheric conditions

- repair of existing diagnostics as well as installation of additional ones

- evacuation of the main chamber down to hard vacuum $\left(<10^{-6}\right.$ Torr $)$ conditions

- extension of the thruster back into the main chamber volume

During the entire process, the thruster was not exposed to pressures above $1.3 \times 10^{-6}$ Torr. During steps when the thruster was being moved, several electrical connections, which had exhibited lower impedance at points during the test, were monitored to ensure the thruster condition was not being altered. The remainder of this section gives details of the individual component repairs that were completed.

A number of diagnostics deteriorated or became inoperable over the course of the LDT. These include: the QCM for measuring backsputtered deposition rates at the thruster location; the internal (nude) hot-cathode ionization gauge by the thruster for measuring facility pressure; the staggered planar probes to measure ion current density and divergence in the thruster plume; the light sources for the in-situ cameras used to image critical components of the thruster; and several vacuum chamber viewports used to view and image the entire thruster assembly. 
The QCM for the LDT is composed of two gold-plated crystals and is equipped with a shutter to cover one of the crystals when not in use. By approximately $12.5 \mathrm{kh}$, both QCM crystals had failed. Figure 2 shows the QCM both pre-test and before the diagnostic repair. It is evident from the photographs that the bottom crystal fractured during the test. The top crystal failed in a similar manner. During the diagnostic repair, the shutter was removed in order to obtain two independent measurements of the backsputter rate. The crystals were replaced with one gold-plated and one aluminum alloy-plated crystal in order to verify that the measured backsputter rate is independent of crystal coating.

The internal pressure gauge for the LDT is a hot-cathode "nude" ionization gauge mounted approximately $0.5 \mathrm{~m}$ to the side of EM3 and is protected within a mesh enclosure. The internal
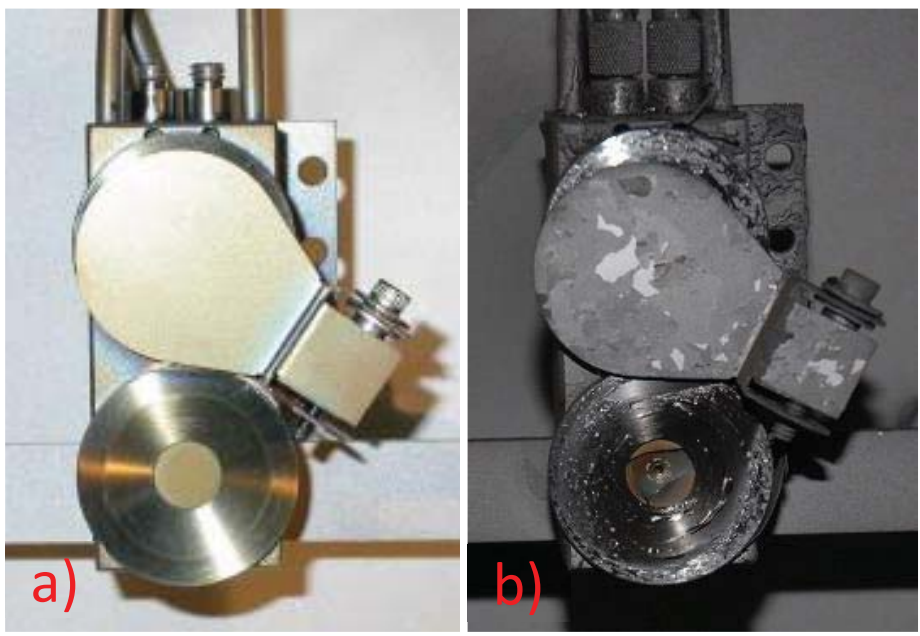

Figure 2. Photographs of the QCM for the LDT both (a) pre-test and (b) before diagnostic repair.

gauge became inoperable after approximately $6.5 \mathrm{kh}$. During the diagnostics repair, it was determined that one of the clamps holding the gauge in place failed, grounding the grid on the gauge. This gauge was removed and replaced with a high-accuracy, hot-cathode ionization gauge. The high-accuracy gauge was mounted approximately $0.7 \mathrm{~m}$ to the side of the thruster, with the inlet positioned at the thruster exit plane and pointing downstream. The inlet was protected from any plasma in the region by a perforated metal plate mounted at the inlet.

The staggered planar probes include three probes at different axial distances from the thruster to measure ion current density and beam divergence. Each probe consists of a collector and a grounded guard ring that are electrically isolated by a hightemperature machinable ceramic. Over the course of the test, there was evidence of a short developing between the collector and guard ring due to backsputtered deposition. ${ }^{25}$ At approximately $14 \mathrm{kh}$, a permanent short developed between collector and facility ground on the nearest probe which could not be removed. During the diagnostic repair, deposition was observed on the front face of the ceramic insulator for all three probes (see Fig. 3). Furthermore, a short between the conductor and braided shield was found in the coaxial cable connecting the nearest probe to the electrical feedthrough. This cable failure was the cause of the permanent short observed on the nearest probe. During the diagnostic repair, the cable was replaced and all three ceramic insulators were cleaned. Electrical isolation between probe collector and facility ground was verified prior to evacuating the facility.

Separate light-emitting diode (LED) lighting was mounted

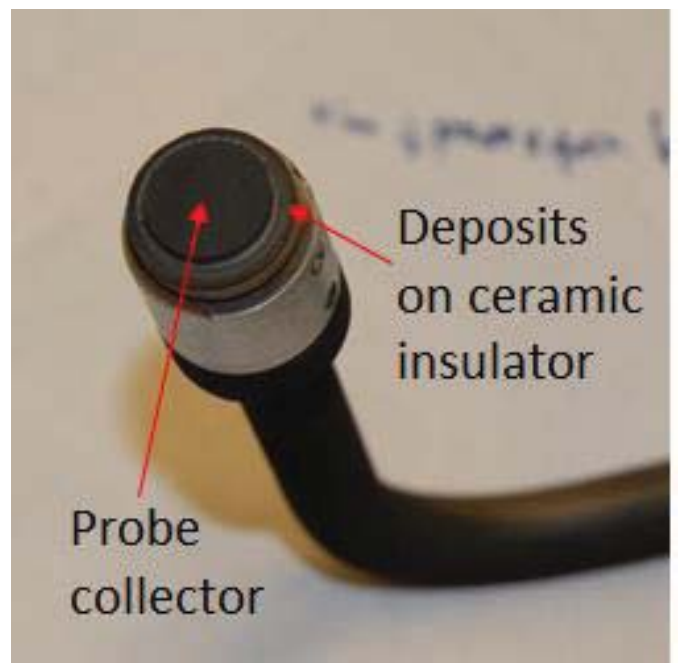

Figure 3. Photograph of the nearest planar probe during the diagnostic repair process with guard ring removed. within the chamber for each in-situ camera that images critical components of the thruster. Between 30 and $40 \mathrm{kh}$, the camera lighting degraded and became insufficient to allow measurement of certain dimensions such as the ion optics cold grid gap and the groove depth around the center radius aperture (CRA). During the diagnostic repair, it was determined that the plastic diffusers/polarizers on multiple LED lights had been damaged and needed to be replaced. Due to the availability of brighter LED lights, many of the lights were simply replaced.

Despite the use of shutters on all the viewports, deposition had accumulated on the glass of two viewports that offered side and front views of the thruster. These viewports were replaced to ensure high-quality photographs of the thruster could be taken from outside the facility.

While the facility was open to atmosphere, a few additions were included on top of the repairs listed above. In order to ensure adequate lighting for thruster imaging, both from the in-situ cameras and from outside the facility, two enhancements were made. First, the side LED light for the CRA was replaced with a brighter, on-axis ring 
LED. This was done to ensure adequate, direct lighting within the pit-and-groove structure of the accelerator grid, a lack of which was an issue in the last 10-20 kh of the test. Second, two linear LED lights were mounted onto the insitu imaging system shroud to provide additional lighting onto the entire thruster when imaged from outside the facility. These lighting enhancements are shown in Fig. 4. Lastly, an auxiliary xenon flow line was placed at the mid-length of the vacuum chamber to facilitate pressure-variation studies. By measuring thruster telemetry and performance as a function of facility pressure, these values can be extrapolated to zero pressure, flight-like conditions. The flow line was connected to a $200 \mathrm{sccm}$ mass flow controller and the outlet was pointed downstream to ensure adequate mixing and a more uniform facility backpressure.
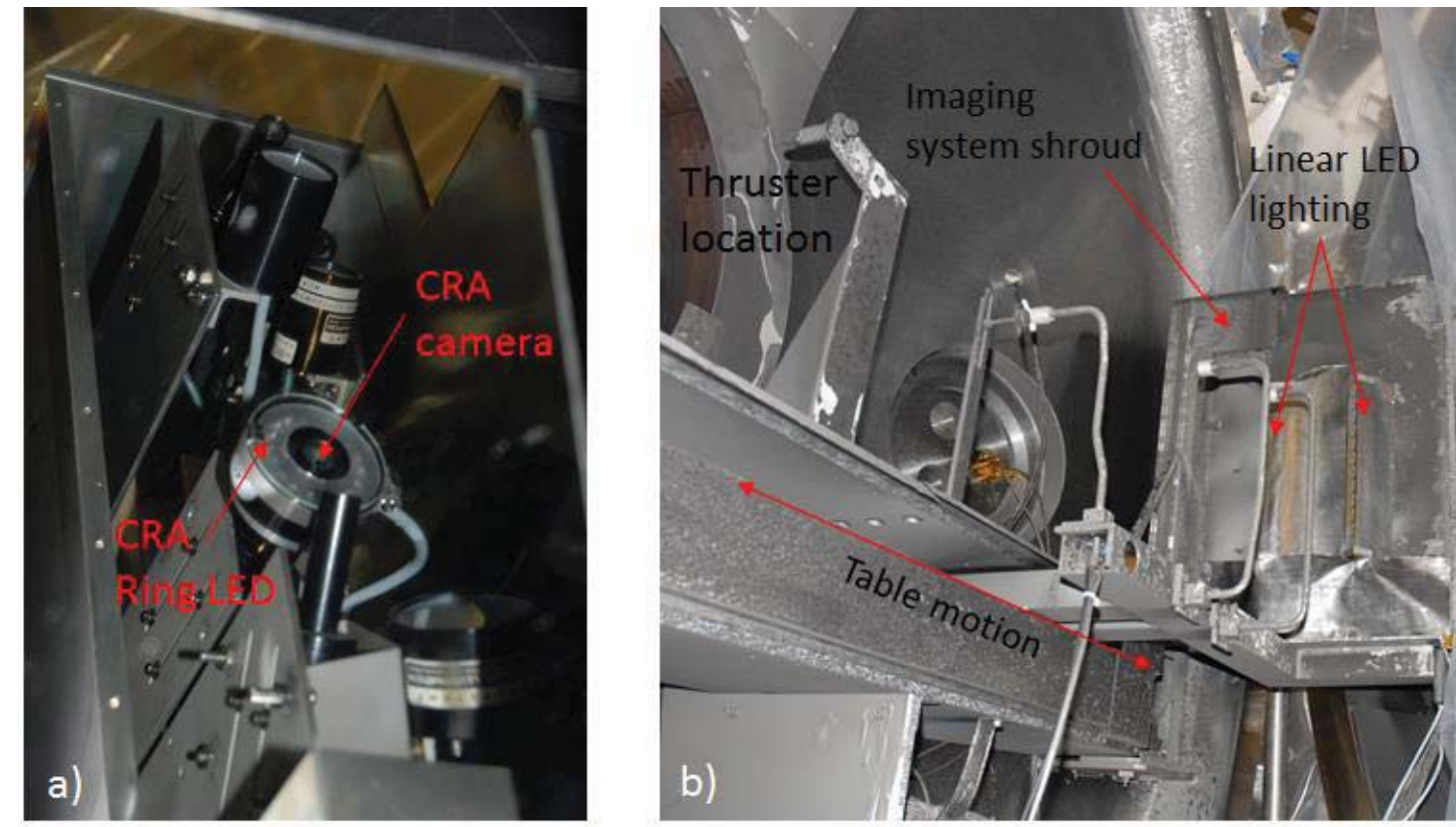

Figure 4. Photographs of enhanced lighting installed during the diagnostic repair process. (a) On-axis ring LED for CRA imaging. (b) Linear LED lighting to provide additional illumination of the thruster for photographs taken outside the facility.

\section{NEXT Long-Duration Test Results - Performance, Erosion, and Model Validation}

The following sections describe the thruster performance resulting from extended operation, measured erosion data, and comparison to model predictions and other ion thruster wear test data for thruster erosion. Performance data will be presented in two ways. Since only eleven operating conditions were characterized for the majority of the test, performance at these conditions will be presented as a function of operating duration in order to illustrate any changes observed over the course of the test. The pre-test and end-of-test performance characterizations were more comprehensive. These data will be plotted as a function of beam current and voltage, illustrating globally how the thruster behaved during pre-test (labeled "pre" in plots) and during end-of-test (labeled "EoT" in plots) conditions.

\section{A. Overall Thruster Performance}

Overall thruster performance of the EM3 has been steady with minimal degradation. Calculated thrust has been constant, with values of $237 \pm 3 \mathrm{mN}$ and a modest increase in input power of $30 \mathrm{~W}$ at full power due to increases in discharge losses. The thruster performance measurement, calculation methodology, and assumptions are described in detail in Refs. 20, 27, 33, and 34. Changes in performance between the PPC in April 2013 and EPC in December 2013 are negligible. In fact, there has been negligible change in performance since the thruster was throttled to full power after completion of the mission profile in May 2010. Time-resolved plots of thruster performance, including thrust, specific impulse, and efficiency can be found in Ref. 29. Relevant performance values for the five throttle points in the LDT mission profile at various throughput milestones can be found in Ref. 32.

A slight increase in input power from 6.83 to $6.86 \mathrm{~kW}$ at full power is attributed to increases in discharge losses which occurred during the first 10,000 hours of operation. Remaining changes in performance are largely attributed to changes in neutralizer flow rate with propellant throughput. Initial increases in performance after the pre-test 
characterization are attributed to changes in neutralizer flow rate. After the pre-test, the neutralizer flow rate was intentionally reduced to improve overall propellant utilization efficiency. During the test, set points from Throttle Table 9 (TT9) were determined to be insufficient to prevent onset of plume mode in the neutralizer over the lifetime of the thruster. To ensure proper flow margin from plume mode transition, the neutralizer flow rate set points were intentionally increased at certain throughput milestones (included in Throttle Table 10 (TT10)). ${ }^{31}$ Other operating conditions show similar trends in performance of constant thrust, slight increases in input power, and slight decreases in specific impulse and thruster efficiency as a function of operating time. The maximum thruster performance variations are $2.5 \%$ in thruster efficiency and $4.2 \%$ in specific impulse. As a reference, measured degradations of less than $9 \%$ for thruster efficiency and specific impulse were observed during the NSTAR ELT. ${ }^{35}$

\section{B. Radial Beam Current Density Profiles}

Current density profiles have not been measured in the NEXT LDT since approximately $13-14 \mathrm{kh}$ due to backsputtered carbon deposition buildup between the collector and guard ring, which created collection area uncertainties. The diagnostic repair which occurred at $50.4 \mathrm{kh}$ has allowed for a final end-of-test characterization of the ion beam exiting the thruster. Figure 5 compares current density profiles between pre-test and end-of-test performance characterizations for four of the five operating conditions in the LDT throttle profile. Data from TL37 exhibits similar trends to those seen at full power. The three staggered probes are at locations of 20, 173, and 238 $\mathrm{mm}$ from the geometric center of the ion optics. No attempts were made to repel charge-exchange ions or account for secondary electron emission from the probe.
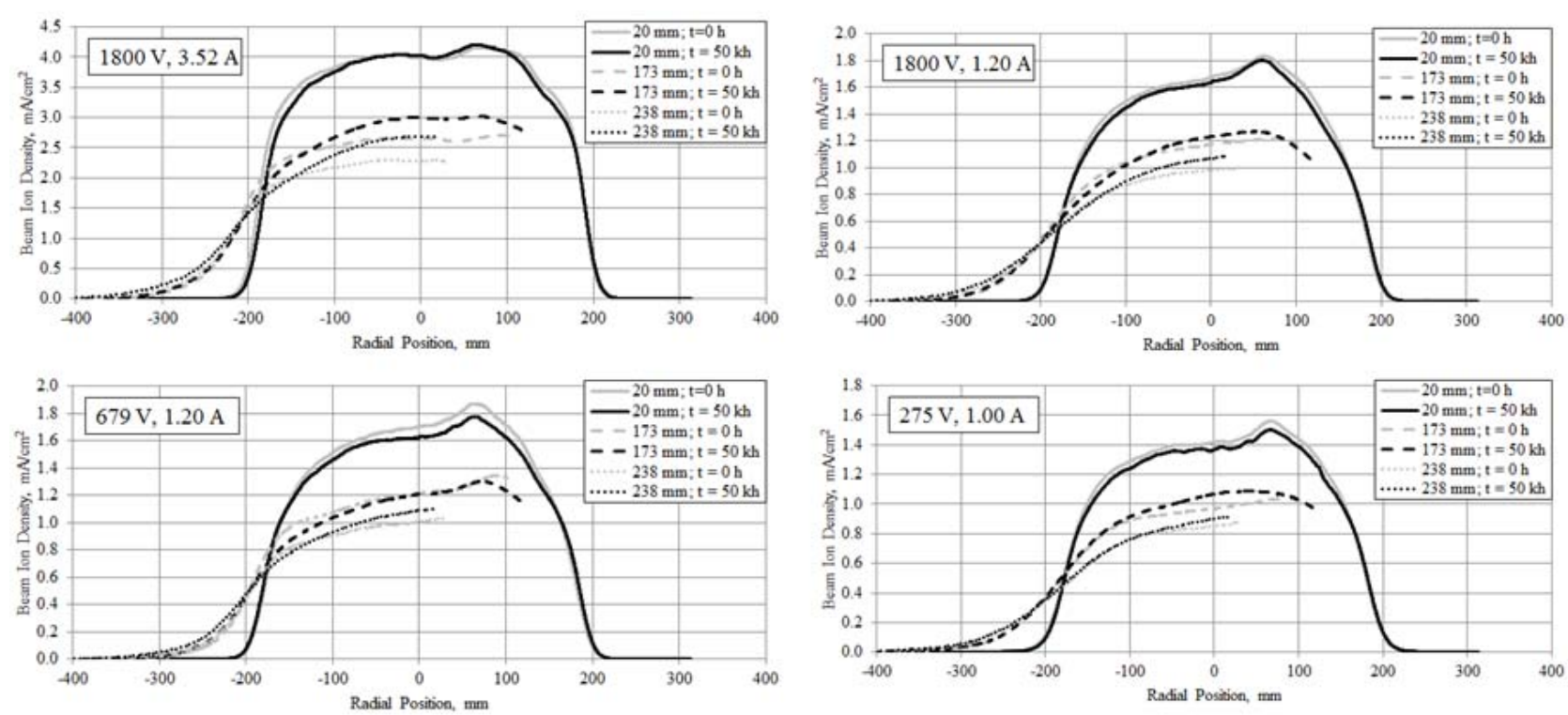

Figure 5. Current density profile comparisons between pre-test and end-of-test performance characterizations at select operating conditions.

While the data at $20 \mathrm{~mm}$ do not exhibit significant differences between 0 and $50 \mathrm{kh}$, the profiles further downstream exhibit differences in shape and peak current density. Profiles at $50 \mathrm{kh}$ exhibit a "rounding" of the shoulder where the current density drops off compared to profiles at beginning-of-life (BOL). Such rounding was previously observed between 0 and $13 \mathrm{kh}$ at full power. ${ }^{25}$ However, the differences in peak heights have not been observed in previous data sets. Distances from the probes to the thruster were measured and verified after the thruster was exposed to atmosphere. A number of potential causes were investigated including: thruster pointing uncertainty due to use of the push-pull rod system for thruster retraction/extension during the diagnostic repair; facility pressure variations over the course of the test; neutralizer cathode proximity to plume mode that would change plasma behavior in the near-field plume; and measurement shunt resistance drift with time. None of these possible causes significantly altered the current density profiles. The differences observed in the profiles further downstream are still under investigation.

Table 2 summarizes the key characteristics of the beam current density profiles at 0,10 , and $50 \mathrm{kh}$ for the five operating conditions in the LDT throttle profile. The characteristics include: the integrated beam current assuming axisymmetry; the error in the integrated beam current when compared to the measured beam current (reasons for this 
error are detailed in Refs. 36 and 37); the peak measured beam current at $20 \mathrm{~mm}$; the beam flatness parameter, defined as the ratio of the average-to-peak ion current densities; and beam divergence angle, defined as the halfangle containing $95 \%$ of the integrated probe current. Values have not significantly changed over the last $40 \mathrm{kh}$ of operation.

Table 2. Measured characteristics of beam current density profiles at the five operating conditions in the NEXT throttle profile. Leftmost values correspond to $t=0 \mathrm{~h}$, middle values correspond to $t=10 \mathrm{kh}$, and rightmost values correspond to $\mathbf{t}=\mathbf{5 0} \mathbf{k h}$.

\begin{tabular}{|l||c|c|c|c|c|}
\hline & TL40 & TL37 & TL05 & TL01 & TL12 \\
\hline Integrated beam current $(\mathrm{A})$ & $4.02 / 3.87 / 3.77$ & $3.84 / 3.73 / 3.77$ & $1.42 / 1.32 / 1.37$ & $1.24 / 1.11 / 1.18$ & $1.40 / 1.34 / 1.34$ \\
\hline Error in measurement $(\%)$ & $14 / 10 / 7$ & $9 / 6 / 7$ & $18 / 10 / 15$ & $23 / 11 / 18$ & $17 / 11 / 11$ \\
\hline Peak beam current $\left(\mathrm{mA} / \mathrm{cm}^{2}\right)$ & $4.16 / 4.18 / 4.21$ & $4.08 / 4.09 / 4.20$ & $1.87 / 1.77 / 1.78$ & $1.56 / 1.45 / 1.50$ & $1.83 / 1.79 / 1.80$ \\
\hline Beam Flatness & $0.83 / 0.83 / 0.82$ & $0.85 / 0.85 / 0.82$ & $0.63 / 0.67 / 0.66$ & $0.63 / 0.68 / 0.66$ & $0.65 / 0.66 / 0.66$ \\
\hline Divergence (degrees) & $24.5 / 25.2 / 27.6$ & $19.9 / 20.3 / 22.7$ & $14.5 / 20.4 / 23.3$ & $27.6 / 28.5 / 28.1$ & $25.7 / 25.5 / 27.8$ \\
\hline
\end{tabular}

\section{Discharge Chamber}

As stated in the previous section, an increase in input power was observed at all conditions, primarily attributed to an increase in discharge losses during the first $10 \mathrm{kh}$ of operation. Figure 6 shows the measured discharge losses at select operation conditions as a function of operating time. Discharge losses have been fairly constant over the last $40 \mathrm{kh}$, with an increase from $122 \mathrm{~W} / \mathrm{A}$ to $130 \mathrm{~W} / \mathrm{A}$ observed during the first $10 \mathrm{kh}$ at full power. This trend is consistent with the observed changes in accelerator grid aperture wear. The increase in discharge losses is likely due to a decrease in neutral density within the discharge chamber from accelerator grid aperture chamfering, increased thermal conductance from the cathode emitter due to barium migration, and surface condition changes of the cathode emitter and anode wall. ${ }^{21}$ Negligible changes in discharge losses were observed due to the diagnostic repair (occurring at 50,453 h). Figure 7 compares the discharge losses at all conditions between the pre-test and end-oftest performance characterizations. At certain low power conditions, a decrease in discharge losses is actually seen at end-of-test conditions compared to pre-test conditions. It is apparent from Fig. 6 that there is higher variability in the discharge loss data at these low power conditions. This trend is likely due to the higher discharge utilization efficiency at these conditions, making the discharge losses more sensitive to subtle flow variations. The increase in discharge losses for all conditions over the course of the test did not exceed $13 \mathrm{~W} / \mathrm{A}$, corresponding to a maximum increase of approximately $8 \%$.

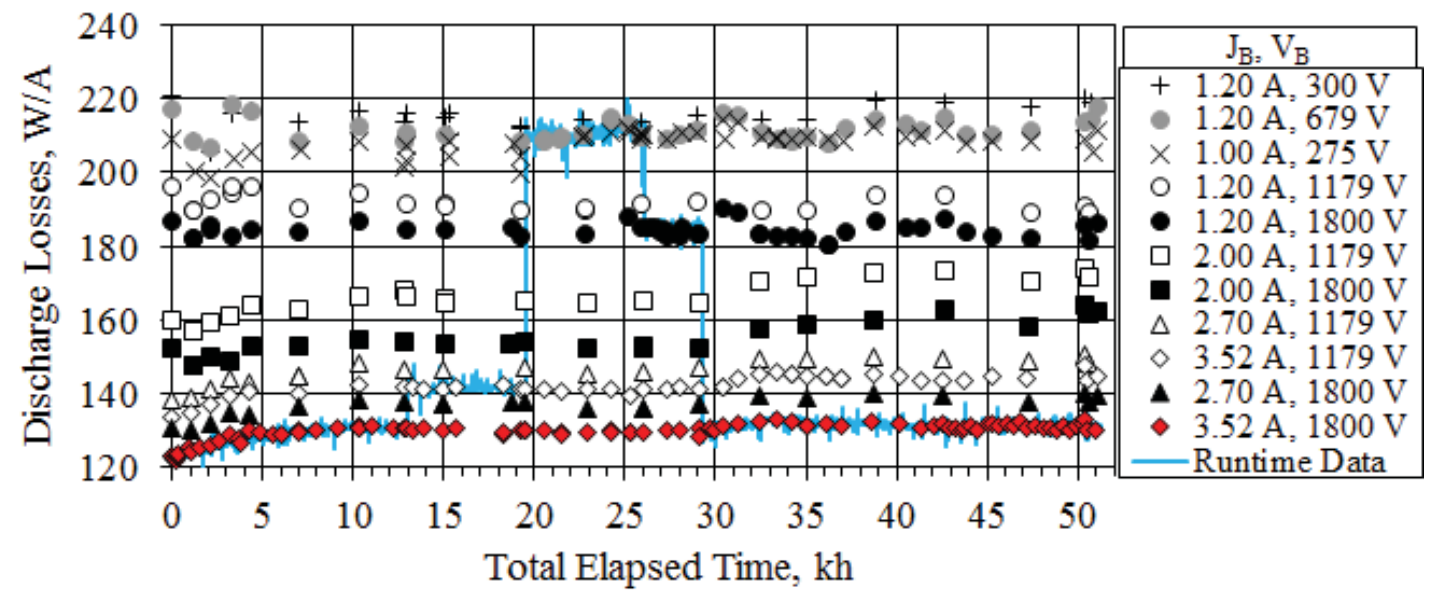

Figure 6. Discharge loss data for the NEXT LDT as a function of operating time. 


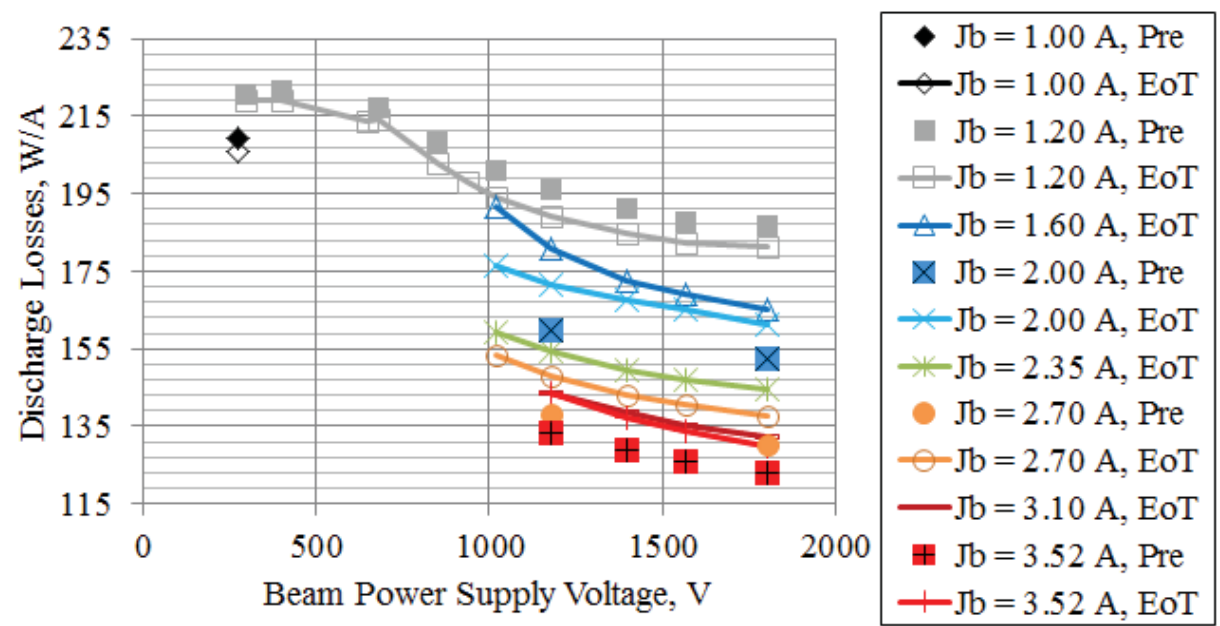

Figure 7. Discharge loss data comparison between pre-test and end-of-test characterizations of the NEXT LDT.

Figures 8 and 10 show the measured discharge voltage and current for select conditions as a function of operating time. As with discharge losses, the discharge voltage and current show modest increases primarily within the first $10 \mathrm{kh}$ of operation. Discharge voltage also appears to be more variable at lower power conditions where the higher discharge utilization efficiency makes it more sensitive to subtle variations in flow rate. Taking this variability into account, the discharge voltage and current did not change significantly as a result of the diagnostic repair. Figures 9 and 11 compare the discharge voltage and current between the pre-test and end-of-test performance characterizations, illustrating the same trends across the throttle table seen in the time-resolved plots. Figure 12 shows the discharge characteristics at two select operating conditions as a function of time. No significant changes occurred after the first $10 \mathrm{kh}$, which is consistent with the other discharge chamber performance data. Also, negligible changes in the shape of the characteristics indicate no change in the magnetic field topology within the discharge chamber. This result is further confirmed at other operating conditions shown in Fig. 13, which compares the pre-test characteristics to those measured during the EPC.

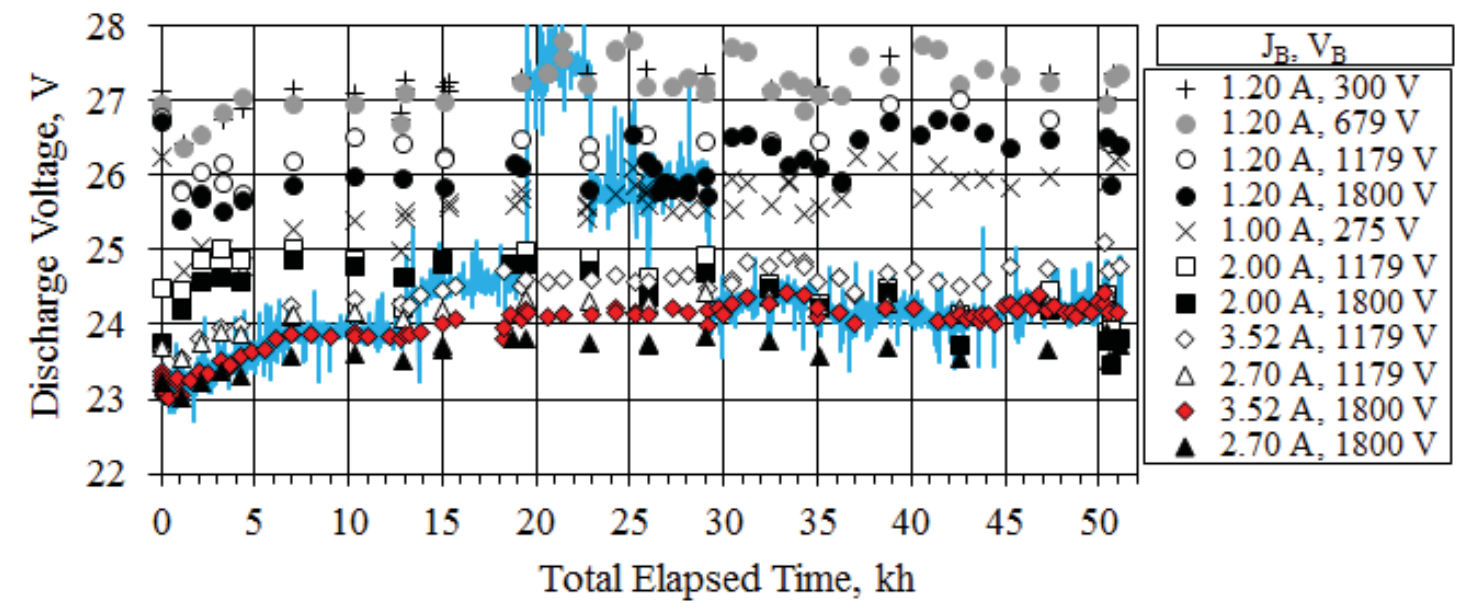

Figure 8. Discharge voltage data for the NEXT LDT as a function of operating time. 


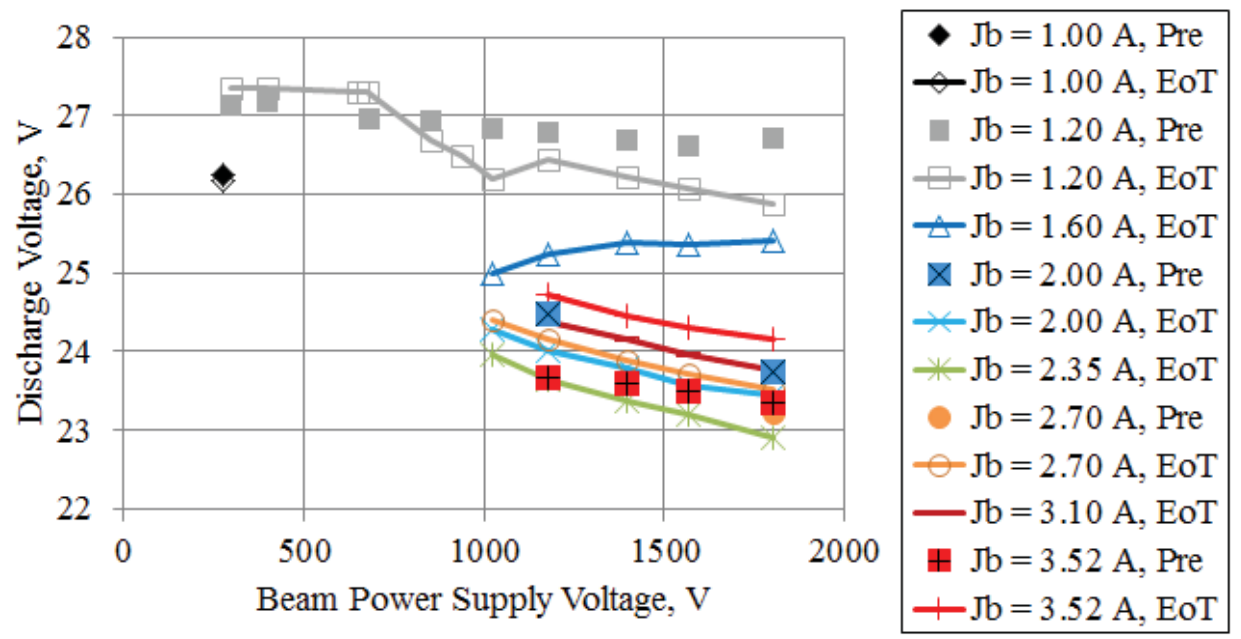

Figure 9. Discharge voltage data comparison between pre-test and end-of-test characterizations.

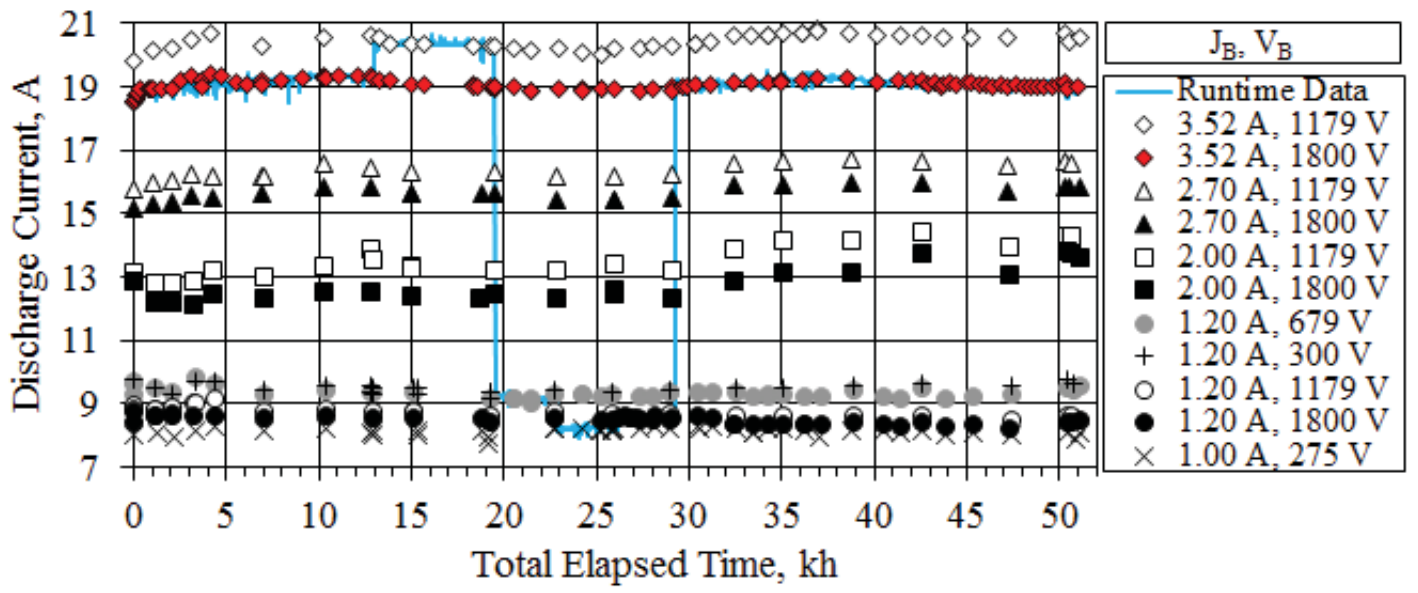

Figure 10. Discharge current data for the NEXT LDT as a function of operating condition.
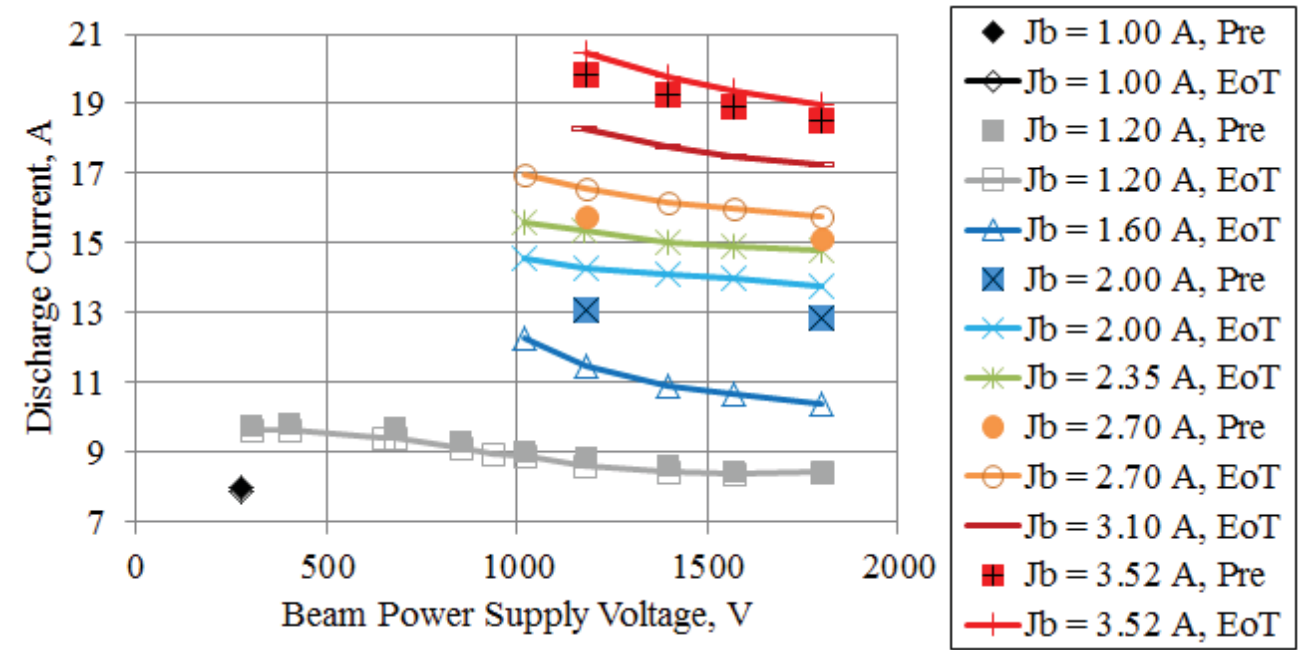

Figure 11. Discharge current data comparison between pre-test and end-of-test characterizations of the NEXT LDT. 


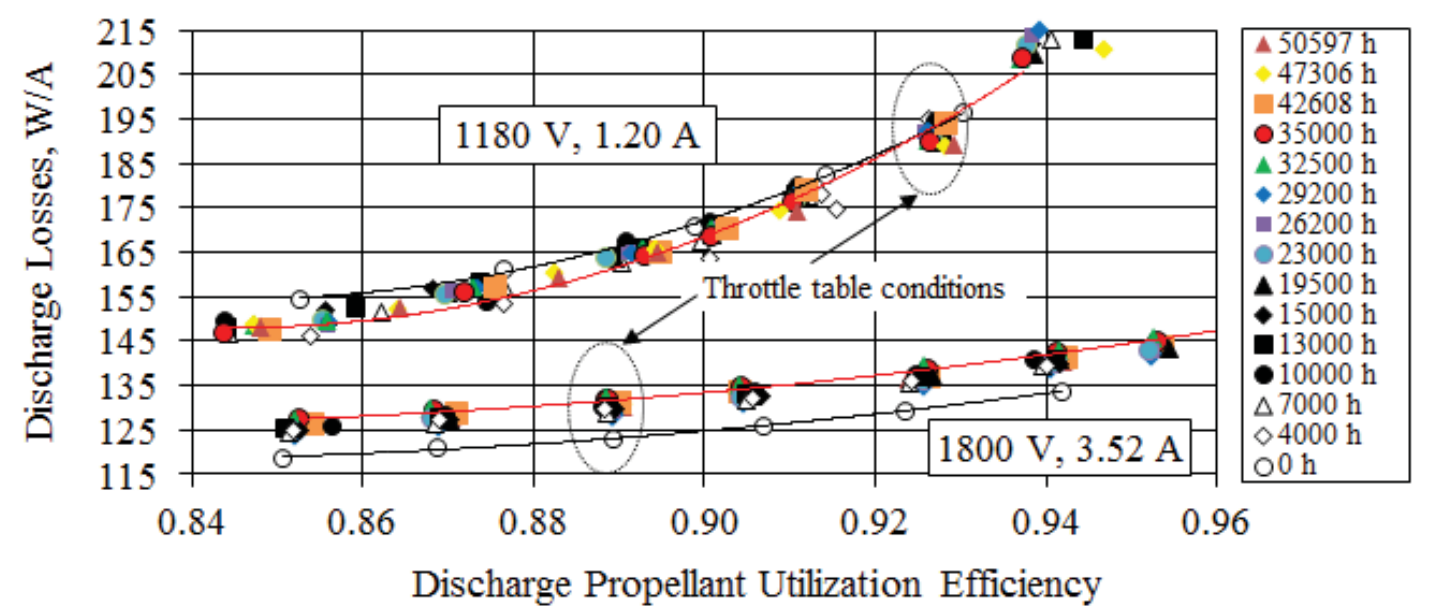

Figure 12. Discharge characteristics of the NEXT LDT as a function of operating time.

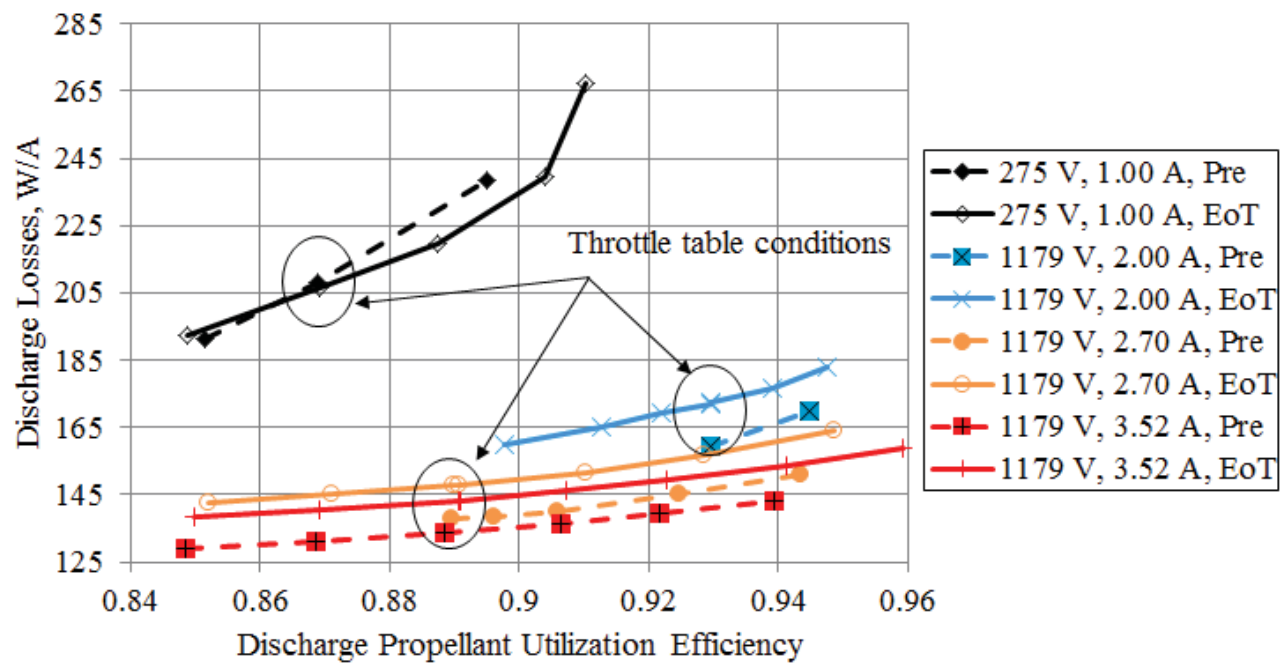

Figure 13. Discharge characteristic comparisons between pre-test and end-of-test performance characterizations of the NEXT LDT.

\section{Discharge Cathode Assembly}

During the NSTAR ELT, severe erosion of the discharge cathode assembly had been observed. After approximately 15,000 hours of operation, the keeper electrode had eroded enough to fully expose the cathode orifice plate, heater coil, and radiation shielding. ${ }^{38}$ Keeper erosion during the NSTAR ELT was characterized by a widening of the keeper orifice, which is in contrast to the NSTAR 8,200 h and NEXT 2,000 h wear tests where the most severe erosion occurred towards the mid-radius of the keeper orifice plate. ${ }^{19,39,40}$ Post-test examination of the NSTAR ELT discharge cathode assembly, shown in Fig. $14^{35}$, revealed complete
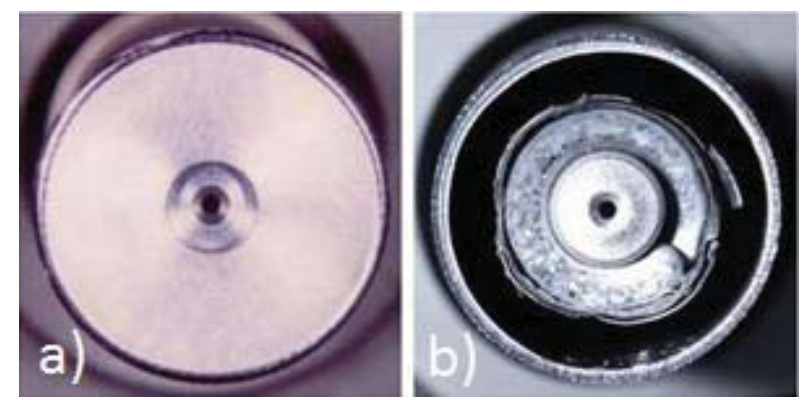

Figure 14. NSTAR ELT discharge cathode assembly front view at (a) BOL and (b) after 30,352 hours of operation. removal of the cathode orifice plate weld joint. The orifice plate was only held on by a 20-50 $\mu \mathrm{m}$ region of thermally-induced fusion between the cathode tube and orifice plate. ${ }^{35}$ Because of the severe erosion of the discharge cathode during the NSTAR ELT, numerous additional potential failure modes were uncovered such as cathode failure due to cathode heater erosion and unclearable grid-to-grid short and/or rogue hole formation due to flaking of the discharge cathode radiation shielding. ${ }^{35}$ 
The primary function of the discharge keeper is to protect the discharge cathode from excessive sputter erosion. Due to results from the NSTAR ELT and the NEXT 2,000 $\mathrm{h}$ wear test, the discharge keeper material on EM3 was changed to graphite, which has a sputter yield an order of magnitude lower than that of molybdenum for a $50 \mathrm{eV}$ ion impact energy. ${ }^{41}$ At the end of the test, the discharge cathode assembly had accumulated a total of 51,724 hours of operation. Figure 15 shows the front view of the NEXT discharge cathode at BOL and at the end of the test, while Fig. 16 shows the measured critical diameters of the cathode assembly as a function of thruster operating time. The cathode orifice
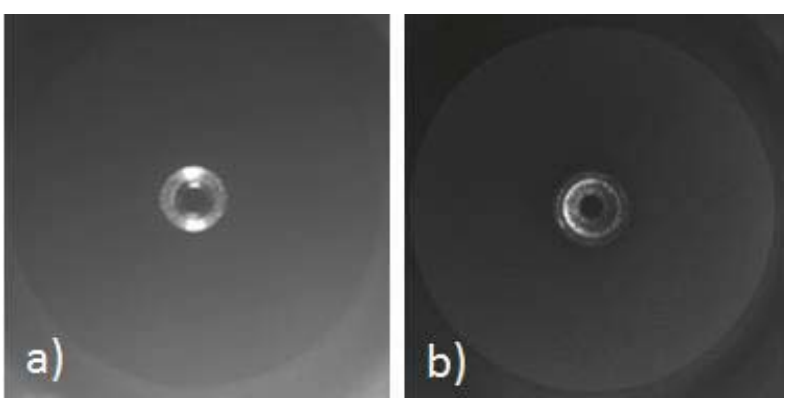

Figure 15. NEXT LDT discharge cathode assembly front view taken with in-situ cameras at (a) 0 hours and (b) after 51,184 hours.

diameter has changed negligibly over the course of the test. Over the course of the last $10 \mathrm{kh}$, the keeper orifice diameter appeared to be decreasing by approximately $5-10 \%$. However, the latest set of measurements with repaired in-situ camera lighting indicates that this trend was likely due to an inability to accurately discern the keeper orifice edge. The latest set of measurements confirms an increase in the cathode orifice chamfer diameter by about $20 \%$. The detailed geometry of the cathode orifice plate, and in particular the orifice chamfer, is unclear from the in-situ images and post-test inspection of the hardware will be necessary to confirm the final dimensions.

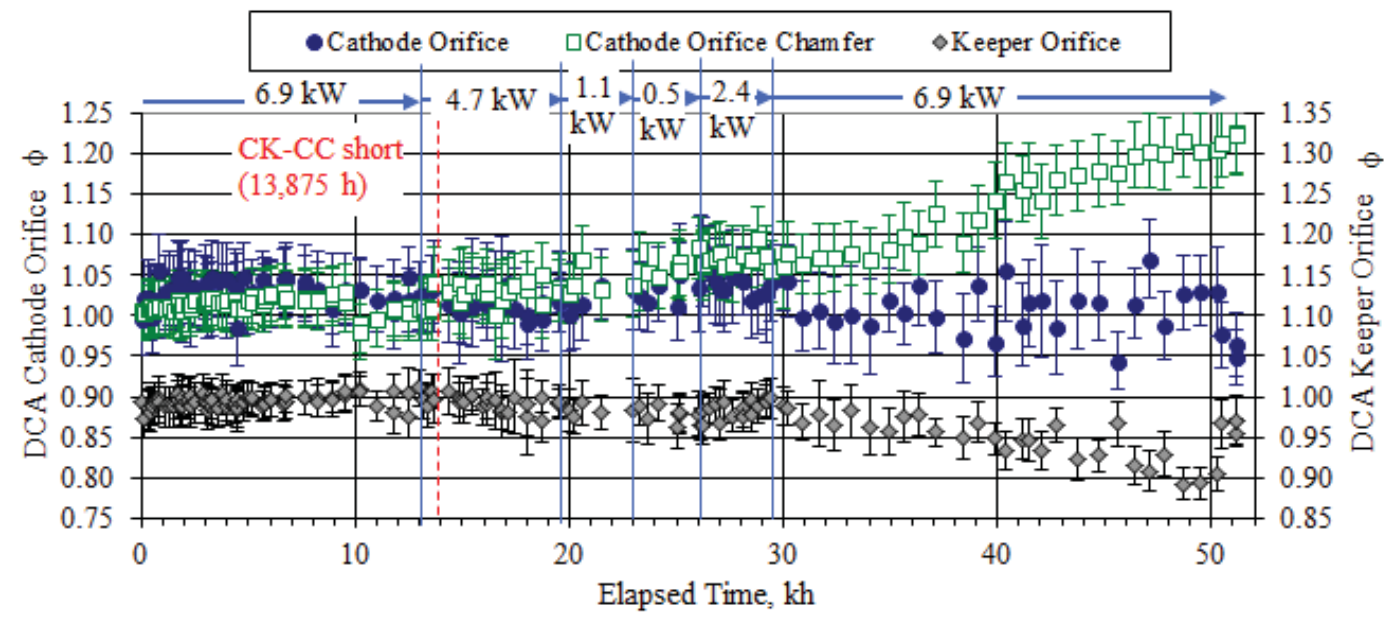

Figure 16. NEXT LDT discharge cathode orifice, cathode orifice chamfer, and keeper orifice diameters as a function of thruster operating time, normalized by BOL dimensions.

While the in-situ images indicate that there is negligible change in the keeper orifice diameter, they are unable to detect any erosion of the downstream surface of the keeper faceplate. As previously mentioned, the discharge keeper erosion on the downstream surface was similar between the NSTAR 8,200 $\mathrm{h}$ and the NEXT 2,000 $\mathrm{h}$ wear tests, with the most severe erosion occurring at radii of $55-60 \%$ and $40 \%$ of the total keeper radius, respectively. ${ }^{19,} 39$, 40 Scaling the molybdenum discharge keeper erosion rate from the NEXT 2,000 $\mathrm{h}$ wear test (depth of $17 \%$ of the keeper thickness after test) with the reduced sputter yield of graphite compared to molybdenum gives a conservative estimate of wear through the keeper faceplate after $>100 \mathrm{kh}$ at full power $\left(>2,000 \mathrm{~kg}\right.$ throughput). ${ }^{17,18,39,41,42}$ Based on the NEXT service life assessment, the keeper thickness near mid-radius for the NEXT LDT discharge cathode is estimated to have eroded by approximately $39 \%$ (see Fig. 17). 


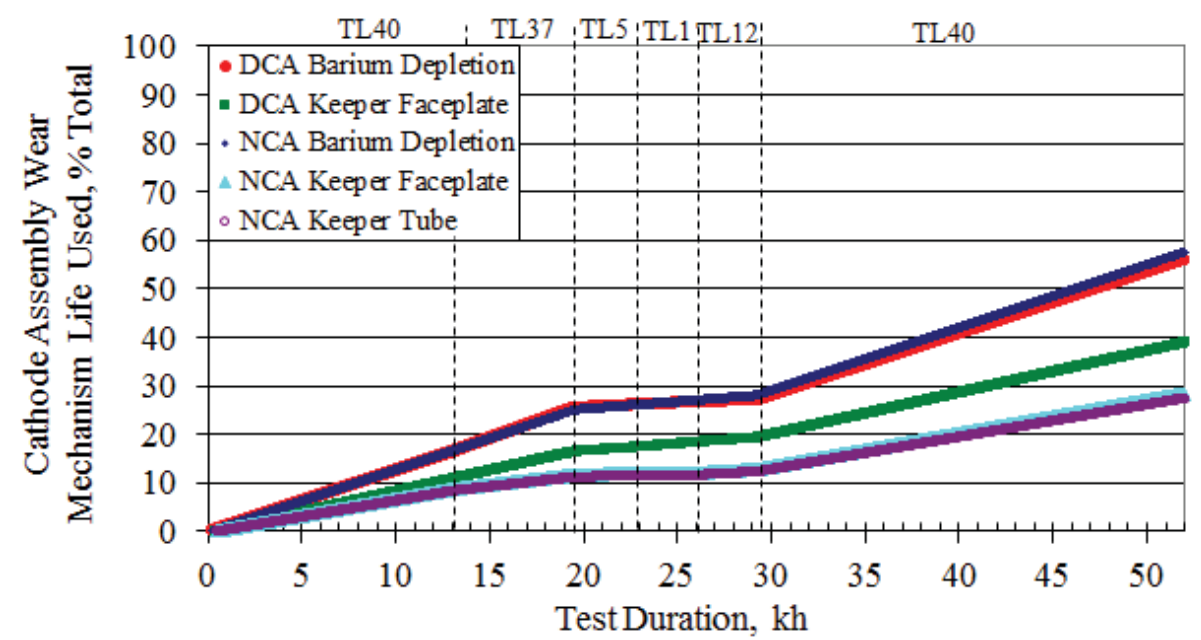

Figure 17. NEXT LDT cathode wear-out mode progressions based upon the NEXT service life assessment.

Intermittent, thermally-induced shorting between the discharge keeper and cathode was observed after 13,875 hours of operation (833 hours after throttling to TL37). The NEXT service life assessment predicted this shorting event and considered its impact on cathode lifetime. ${ }^{17,18}$ Shorting of the discharge keeper to cathode was observed during the NSTAR ELT, and coincided with the onset of anomalous discharge cathode assembly erosion. ${ }^{35}$ Electrical shorting of the discharge keeper to cathode was also expected during the NEXT LDT due to findings from the NEXT 2,000 $\mathrm{h}$ and the High Power Electric Propulsion (HiPEP) 2,000 h wear tests performed at NASA GRC. ${ }^{19}$,

${ }^{43}$ Post-test analyses revealed tungsten deposits on the upstream surface of the keeper faceplate near the orifice of 40 $\mu \mathrm{m}$ and $70 \mu \mathrm{m}$ thicknesses for the NEXT and HiPEP wear tests, respectively. ${ }^{43,}{ }^{44}$ If linear growth is assumed, the deposition rate based on the NEXT and HiPEP wear tests would have resulted in bridging the estimated operating gap between the NEXT LDT keeper and cathode faceplates after approximately $10-30 \mathrm{kh}$. The discharge keeper voltage for select operating conditions as a function of time is shown in Fig. 18. The keeper remained shorted to cathode for an extended period from approximately $46-50 \mathrm{kh}$, with the short clearing only during performance testing at low power conditions. During this time, from $47.8-50.3 \mathrm{kh}$, the short developed from being thermallyinduced to more of a consistent short which remained even at room temperature. This is believed to have been caused by anomalous pressure excursions in excess of 300 mTorr during facility regenerations, which may have disturbed any material between the keeper and cathode faceplates responsible for the short. ${ }^{32}$ A similar pressure excursion is believed to be the cause of the short clearing after $50.3 \mathrm{kh}$. This excursion immediately preceded the United States government shutdown in October 2013, during which the thruster remained off within the facility operating on a reduced number of pumps for a period of 2.5 weeks. Determination of the source of this short is a critical task of the post-test inspection and analyses, since the consistent short resulted in longer cathode ignition times. $^{32}$

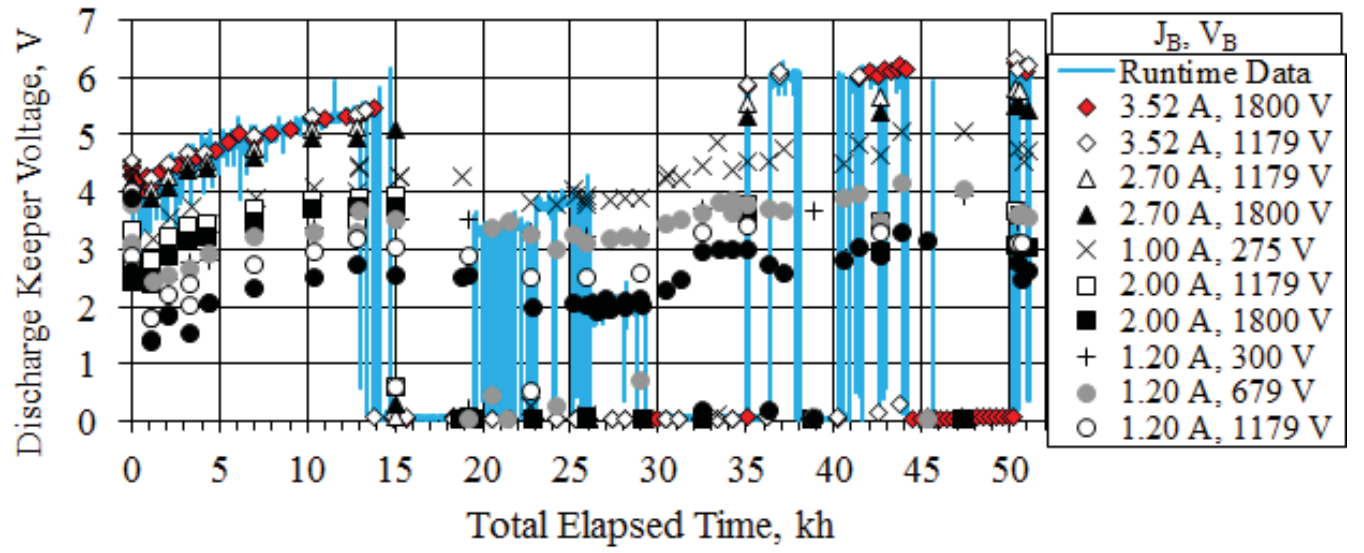

Figure 18. NEXT LDT discharge keeper voltage data as a function of thruster operating time. 
Over the course of the test, the discharge has been ignited a total of 350 times, with an average duration of 4.9 minutes between application of heater current and discharge ignition. Figure 19 shows the discharge ignition time as a function of thruster operating time for the NEXT LDT. Discharge cathode ignitions beyond the nominal $3.5-6$ minute durations are attributed to: absorbed moisture during facility regenerations (eliminated by a $4 \mathrm{sccm}$ xenon purge through the cathode during regenerations), thermally-induced heater open circuits due to loss of a current return path (eliminated in the PM cathode design by a hard current return), and keeper shorting to cathode. ${ }^{28}$ During the time when the consistent short was present, ignition times increased to $8-17$ minutes. Once the consistent short was cleared and returned to manifesting as a thermally-induced short, ignition times returned to $3.5-10$ minutes. Since the consistent short resulted in longer ignition times, it is critical to determine the nature of the material causing the short during the post-test inspection of the hardware. While it appears that facility regenerations exacerbated the short, the source of the material is likely from the thruster and thus this short could manifest itself in flight. Methods to mitigate the extended ignition durations resulting from this short are actively being investigated. Lastly, model predictions for other cathode wear-out modes are shown in Fig. 17, indicating barium depletion on the NEXT LDT discharge cathode of approximately $55 \% .{ }^{17,18}$

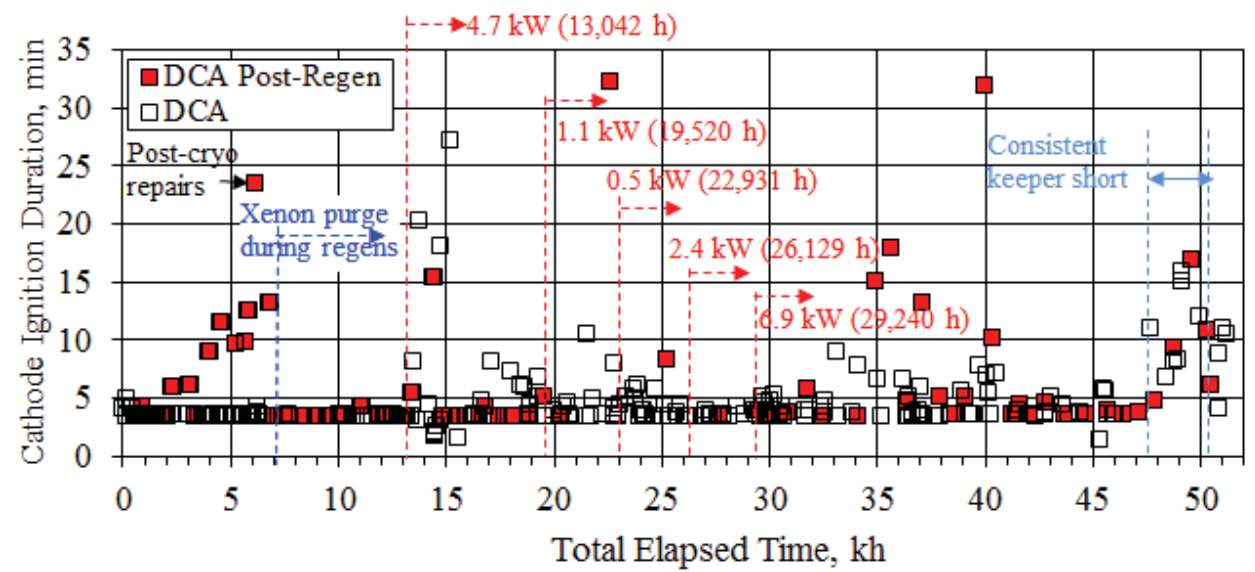

Figure 19. NEXT discharge cathode ignition duration as a function of thruster operating time.

\section{E. Neutralizer Cathode Assembly}

The total operating duration of the neutralizer cathode on the NEXT LDT is 51,771 hours. Figure 20 shows the neutralizer keeper voltage at select operating conditions as a function of time. The keeper voltage dropped during the first $19.5 \mathrm{kh}$ of operation when the thruster was operated at a fixed emission current of 6.52 A. This drop was more significant at lower emission (and beam) currents, as the keeper voltage dropped by only $0.5 \mathrm{~V}$ at full power during the first $10 \mathrm{kh}$ of operation. This drop in keeper voltage also coincides with a loss of neutralizer flow margin, shown in Fig. 23. Both these trends are presently attributed to changes in the neutralizer cathode orifice geometry. The application of a 2-D axisymmetric model of the neutral gas and plasma within hollow cathodes for the NEXT LDT neutralizer reveals that the anticipated erosion of the neutralizer orifice is sufficient to cause the observed change in keeper voltage. ${ }^{45}$ In-situ camera images indicate that the minimum diameter of the cathode orifice has not changed with time. However, the camera is incapable of capturing the profile of the orifice. Therefore, the neutralizer orifice geometry must be measured during post-test inspection of the hardware and compared to the pretest profile. A decreasing keeper voltage of similar magnitude was also observed during the NSTAR ELT at full power. ${ }^{35,46}$ Over the course of the test, the neutralizer was ignited a total of 348 times with an average duration of 3.7 minutes between application of heater current and ignition. All ignitions occurred within 6 minutes of applying the heater current. 


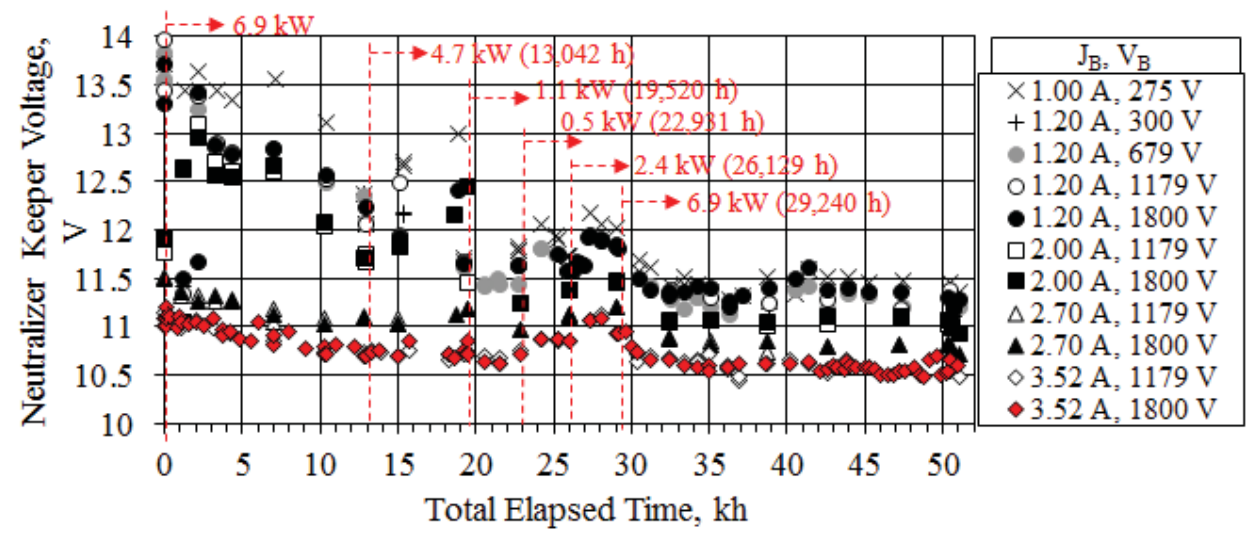

Figure 20. Neutralizer keeper voltage at select operating conditions as a function of thruster operating time for the NEXT LDT.

Neutralizer cathode orifice clogging at low emissions currents has been difficult to predict, thus requiring experimental investigation. Neutralizer emission currents are at their lowest at low power, low beam current set points. Neutralizer orifice clogging was not observed during the extent of the NEXT LDT, despite a total of 9,700 hours of operation at low emission currents. Figure 21 compares the in-situ camera image of the neutralizer cathode orifice at BOL and at the end of the test. Figure 22 shows the measured neutralizer cathode orifice, cathode orifice chamfer, and keeper orifice diameters as a function of thruster operating time. Negligible changes have been observed in the cathode and keeper orifice diameters, while a $20 \%$ increase in cathode orifice
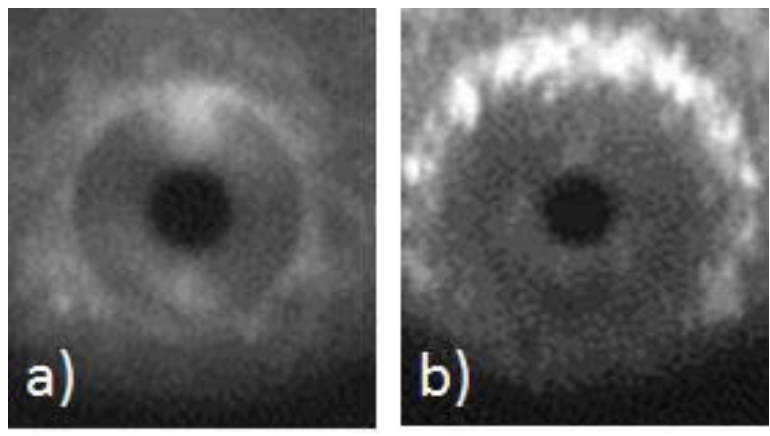

Figure 21. Neutralizer cathode orifice of the NEXT LDT taken with in-situ cameras at (a) 0 hours and (b) after 51,184 hours. chamfer diameter has been observed since BOL.

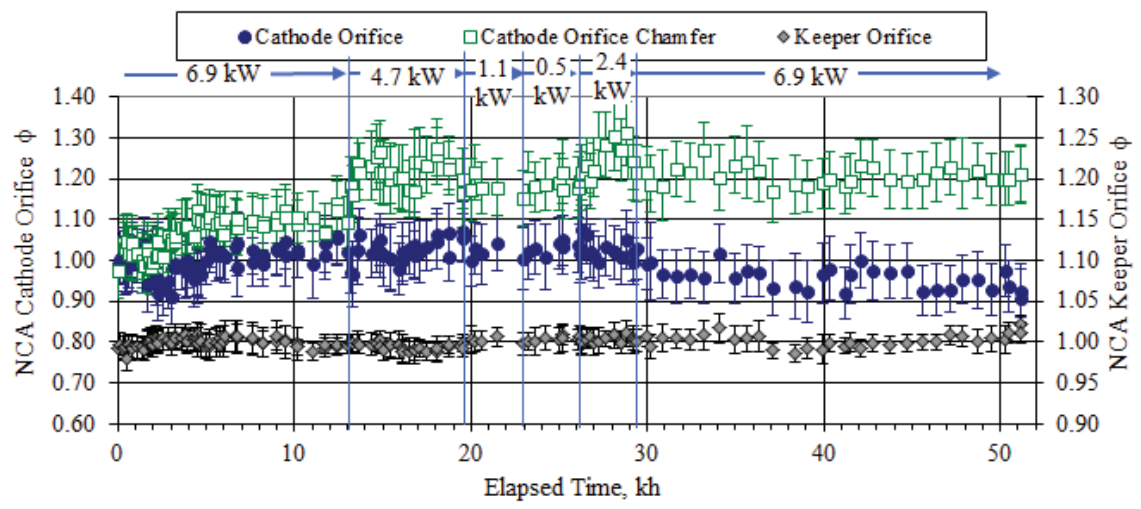

Figure 22. Neutralizer cathode orifice, cathode orifice chamfer, and keeper orifice diameters as a function of thruster operating time. Values have been normalized by BOL dimensions.

The primary performance degradation of the NEXT LDT has been the loss of flow margin on the neutralizer cathode with thruster operating time. Figure 23 shows the flow margin from plume mode for the NEXT LDT neutralizer as a function of thruster operating time. A drop in flow margin was observed at all beam currents, occurring primarily during the first $19.5 \mathrm{kh}$ when the neutralizer was operated at a constant total emission current of 6.52 A. Loss of flow margin at the lower beam currents was significant enough that the flow rates at TT9 were no longer sufficient to keep the neutralizer out of plume mode. Due to the small flow margin at low emission currents at BOL, design modifications were incorporated into the prototype-model (PM) neutralizer that yields higher flow margins at these currents. ${ }^{13}$ These modifications also resulted in lower margins at higher emission currents; however, this change was deemed acceptable due to the substantial margins that had existed at these currents. The 
design change also resulted in a $1 \mathrm{~V}$ increase in the magnitude of the coupling voltage. ${ }^{13}$ In order to provide additional margin, a new throttle table (TT10) was released which increases the neutralizer flow rate at various thruster throughput milestones. This new throttle table is detailed in Ref. 31. In order to determine the flow margin for a PM neutralizer operated in the LDT mission profile, the LDT data was shifted based upon the difference between the pre-test characterization of the EM3 neutralizer and two PM neutralizers. ${ }^{13,20,31}$ These changes correspond to a shift up in flow margin of the LDT data at low power of up to $0.5 \mathrm{sccm}$ and a shift down at full power by $0.3 \mathrm{sccm}$. These shifts are reflected in Fig. 24, which shows the predicted flow margin of a PM neutralizer operated in the LDT mission profile. These data include the flow set point increases detailed in TT10. Figure 24 shows that at least $0.4 \mathrm{sccm}$ margin is maintained during the course of the LDT given the design changes to the PM neutralizer and the use of TT10. It is worth noting that TT10 does not increase the flow set point past $450 \mathrm{~kg}$ throughput. ${ }^{31}$ Despite this, adequate flow margin is maintained past $900 \mathrm{~kg}$ throughput. It appears that degradation of the neutralizer has been negligible since $650 \mathrm{~kg}$, indicating that perhaps the neutralizer orifice has reached a steady-state geometry. Figure 25 compares the transition flow rates for the EM3 neutralizer between the pre-test and the end-of-test characterizations. Flow rate set points for TT9, which also correspond to BOL flow rates, as well as TT10 at $450 \mathrm{~kg}$ are included for comparison. It is evident from the figure that TT10 provides margin at all beam currents even without the design modifications to the PM neutralizer. These modifications merely increase the margin at lower beam currents.



Figure 23. NEXT EM neutralizer flow margin data as a function of thruster operating time, assuming fixed neutralizer flow rates from BOL (TT9). Measurement error is $\pm 0.1 \mathrm{sccm}$.

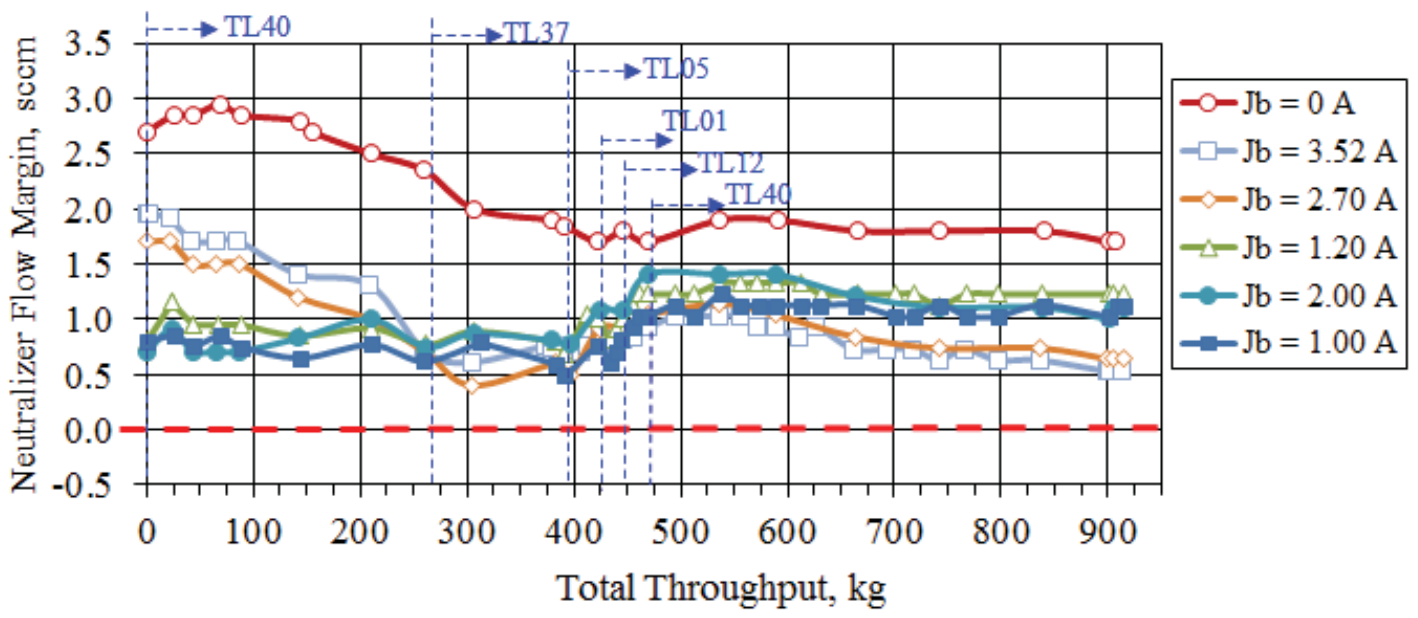

Figure 24. Anticipated NEXT PM neutralizer flow margin data as a function of thruster operating time, operated in the NEXT LDT throttle profile. Measurement error is $\pm 0.1 \mathrm{sccm}$. 


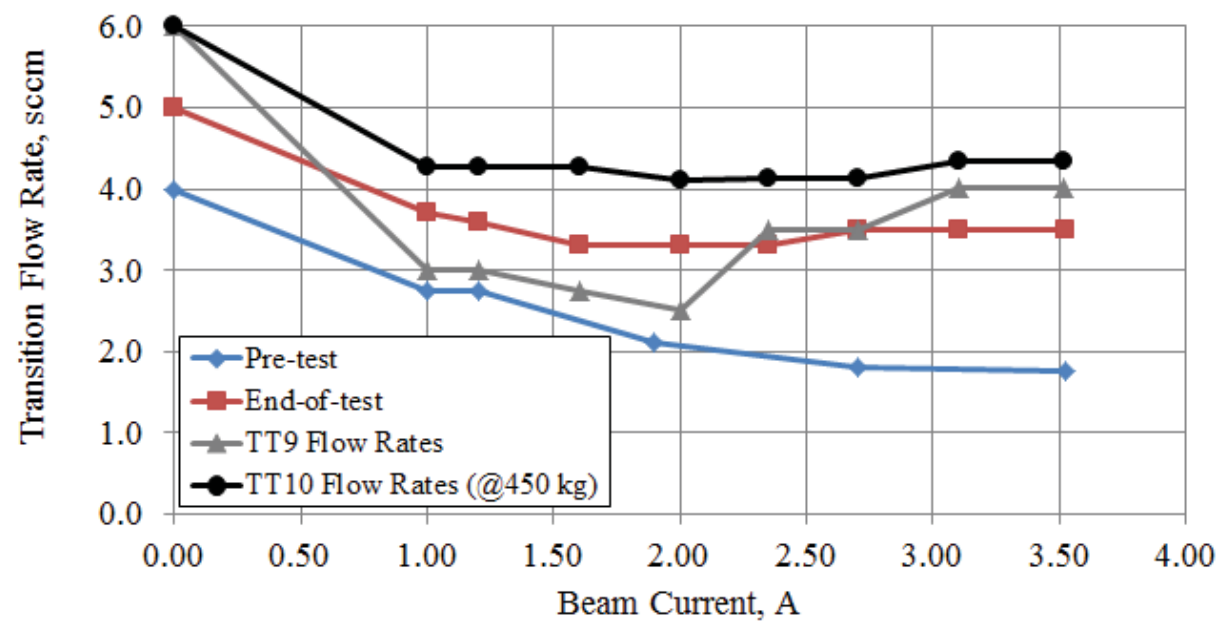

Figure 25. Comparison of the neutralizer transition flow rate as a function of beam current between the pre-test and endof-test performance characterizations of the NEXT LDT. Flow set points at BOL (TT9) and after $450 \mathrm{~kg}$ throughput (TT10) are shown for reference.

While TT10 provides sufficient flow margin from the onset of plume mode for the NEXT neutralizer, the increase in flow set point with throughput is a source of reduced thruster efficiency (as much as $2-3.5 \%$ decrease at lower power operating conditions). Therefore, it is beneficial to investigate the alternative approach of increasing the neutralizer keeper current set point to gain additional flow margin. This approach avoids reduced thruster efficiency since the corresponding increase in electrical power is negligible compared to overall input power to the thruster.

The nominal keeper current in TT10 is $3.0 \mathrm{~A}$ at all operating conditions, while the maximum total emission current is $6.52 \mathrm{~A}$ (corresponding to a beam current of $3.52 \mathrm{~A}$ ). In the present investigation, the maximum total emission current was limited to $6.52 \mathrm{~A}$ in order to avoid possibly altering the state of the LDT neutralizer by running it far outside of its normal operating regime during the test. Furthermore, the maximum keeper current was limited to $4.0 \mathrm{~A}$ as this approaches the limit of the PPU's neutralizer keeper supply. Figure 26 shows the transition flow rate of the LDT neutralizer as a function of total emission current for various beam currents. By comparing to the TT9 flow rates in Fig. 25, it is evident that a keeper current of 4.0 A provides insufficient margin at most conditions to keep the neutralizer out of plume mode at end-of-test conditions using TT9 flow rates. Two interesting trends can also been seen in Fig. 26. First, at low beam currents and high keeper currents, the transition flow rate follows a fairly linear trend with total emission current, independent of beam current. Second, at high beam currents and moderate keeper currents, the transition flow rate follows a linear trend whose slope is independent of beam current, but an offset that is a function of beam current. Closer inspection indicates that these two behaviors are dependent upon the ratio of beam current to total emission current. For conditions where $\mathrm{J}_{\mathrm{B}} /\left(\mathrm{J}_{\mathrm{B}}+\mathrm{J}_{\mathrm{NK}}\right) \leq 0.4$, the transition flow rate follows the first trend and is dominated by total emission current. For conditions where $J_{B} /\left(J_{B}+J_{N K}\right) \geq 0.4$, the transition flow rate follows the second trend and is dominated by beam current. Additional measurements on other NEXT hardware and detailed modeling of the neutralizer would be necessary to determine the underlying cause of this behavior and if it is specific to the LDT neutralizer. Regardless, the data shown in Fig. 26 can be used to determine the increase in flow margin obtained by modulating the neutralizer keeper current. 


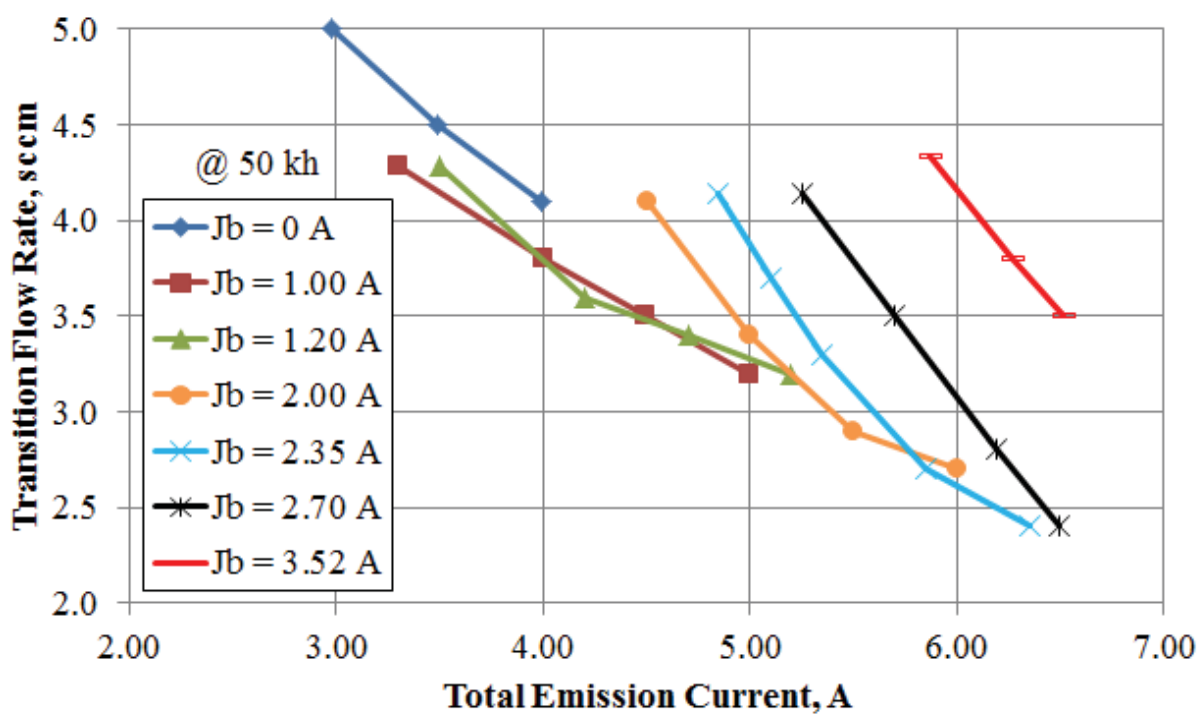

Figure 26. End-of-test characterization of the neutralizer transition flow rate as a function of total emission current for select beam currents.

\section{F. Ion Optics Assembly}

Figure 27 shows the accelerator grid current for select operating conditions as a function of thruster operating time. An initial decrease in accelerator grid current was observed at the beginning of the test due to loss of grid material from erosion. This loss of material was primarily restricted to apertures near the outer radius of the grid. ${ }^{24}$ As the downstream edges of the apertures are chamfered, the reduced grid material results in a slight decrease in accelerator grid current. This reduction in grid current is more apparent in Fig. 28, which compares the accelerator grid current between the pre-test and end-of-test performance characterizations. Slight increases in accelerator grid current were observed since 29,240 hours when the thruster was throttled back to full power. This is thought to be due to filling in of the erosion sites caused by overfocusing at the outer radius apertures during extended operation at TL12, which was observed with the in-situ camera images. No significant changes were observed due to the diagnostic repair.

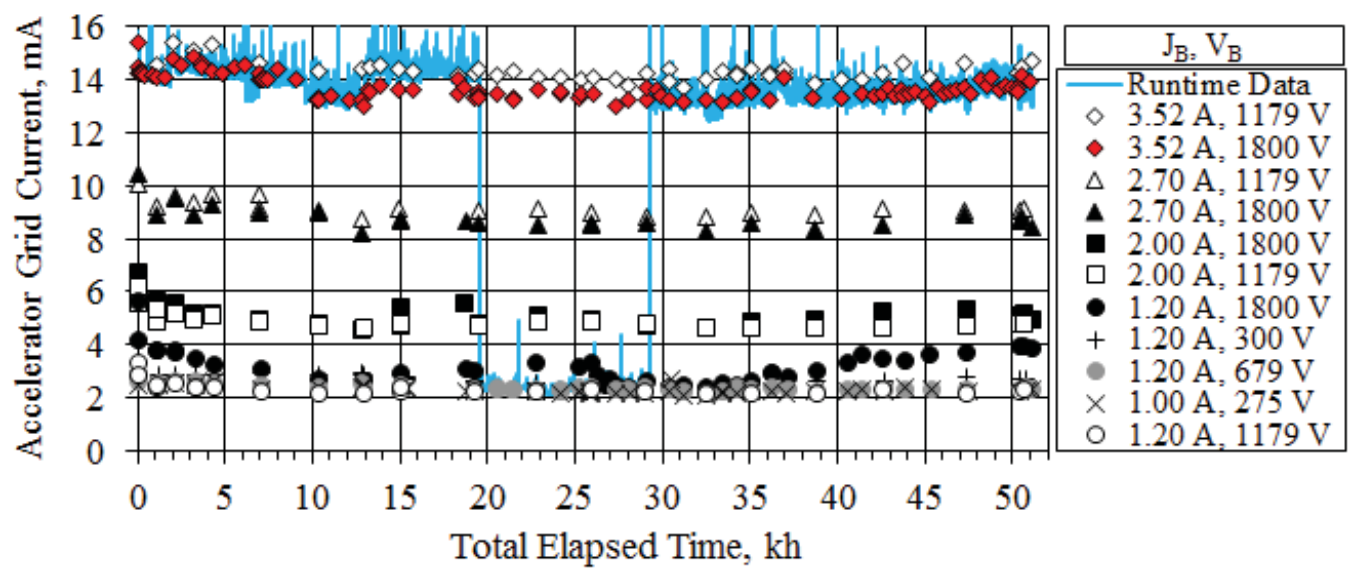

Figure 27. NEXT LDT accelerator grid current data as a function of operating time. 


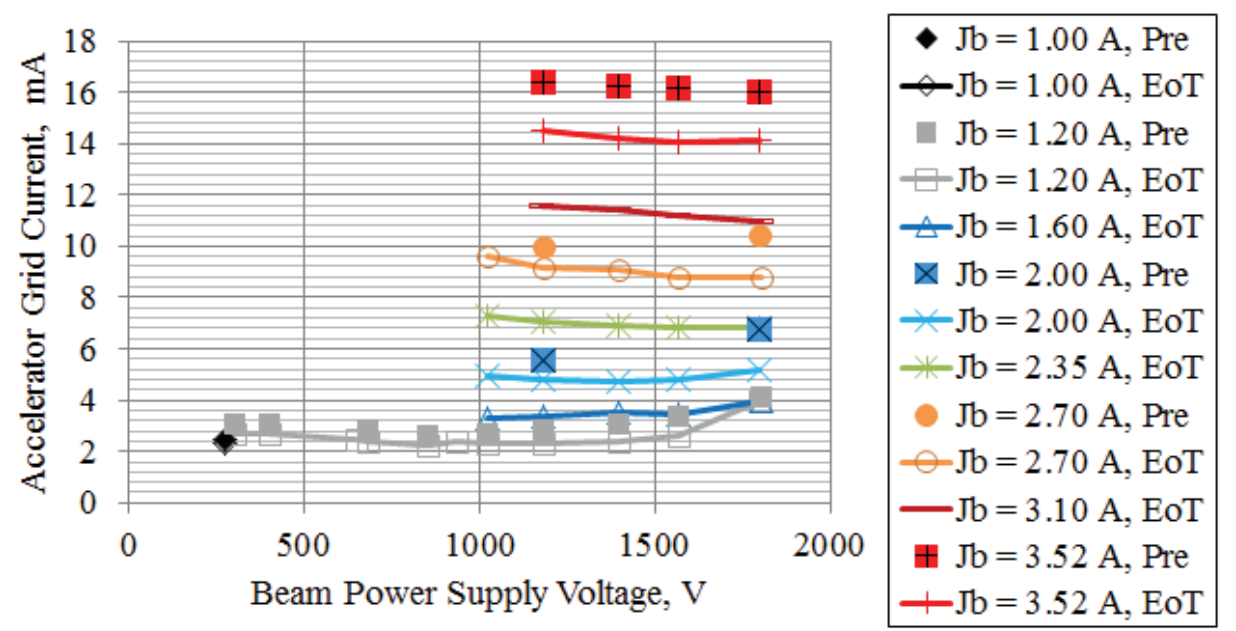

Figure 28. Comparison of accelerator grid current data between pre-test and end-of-test performance characterizations for the NEXT LDT.

Electron backstreaming and perveance margins, as well as the screen grid ion transparency, throughout the test are shown in Figs. 29, 32, and 34, respectively. The measurement techniques for these three quantities are described in detail in Ref. 36. By the end of the LDT mission-representative throttle profile, the electron backstreaming margin at full power was within $1 \mathrm{~V}$ of the BOL value, indicating negligible change within the measurement uncertainty. By comparison, the first-failure mode encountered during the NSTAR ELT was an inability to prevent electron backstreaming after 25,700 hours (211 kg throughput). ${ }^{46}$ The failure mode has been mitigated in NEXT by improved, second-generation ion optics and discharge chamber designs. There has been a modest but discernable trend in electron backstreaming margin while the thruster is operated at full power for extended duration. These two full-power throttle segments, with operation up to $13 \mathrm{kh}$ and since $29.2 \mathrm{kh}$, show a measurable increase in electron backstreaming margin. These increases in margin are also seen in Fig. 30, which compares the electron backstreaming limit (accelerator grid voltage at which electron backstreaming occurs) between the pre-test and endof-test performance characterizations. This trend is possibly due to an increase in accelerator grid thickness as well as slight deposits within aperture barrels from backsputtered carbon. A second explanation is a possible change in plasma properties near the downstream surface of the accelerator grid due to neutralizer proximity to plume mode operation. Inspection of the LDT performance data indicates a correlation between electron backstreaming margin and neutralizer flow margin from plume mode. In order to further investigate this correlation, the electron backstreaming margin was measured at various neutralizer flow set points above the transition flow rate. The results of this investigation are shown in Fig. 31, which plots the gain in electron backstreaming margin above the margin at a high neutralizer flow rate $(8 \mathrm{sccm})$ as a function of the neutralizer flow margin. With the exception of $\mathrm{J}_{\mathrm{B}}=1.20 \mathrm{~A}$, a significant increase in electron backstreaming margin is observed at all beam currents as the neutralizer approaches plume mode. At full power, the neutralizer flow margin decreased from $2.2 \mathrm{sccm}$ to $1.0 \mathrm{sccm}$ during the first $13 \mathrm{kh}$, while at lower power conditions the flow margin decreased from $0.5 \mathrm{sccm}$ down to $0.1 \mathrm{sccm}$. After 29.2 $\mathrm{kh}$, the flow margin for all operating conditions remained between 0.5 and $1.2 \mathrm{sccm}$. From Fig. 31, these variations in flow margin may only account for at most 2-3 V change in electron backstreaming margin at full power, while the observed increases in margin for the two full-power segments are $6 \mathrm{~V}$ and $13 \mathrm{~V}$. Regardless of the cause, this is a second-order effect and the electron backstreaming margin is expected to remain roughly constant in flight due to lack of accelerator aperture cusp erosion or change in ion optics grid gap. 


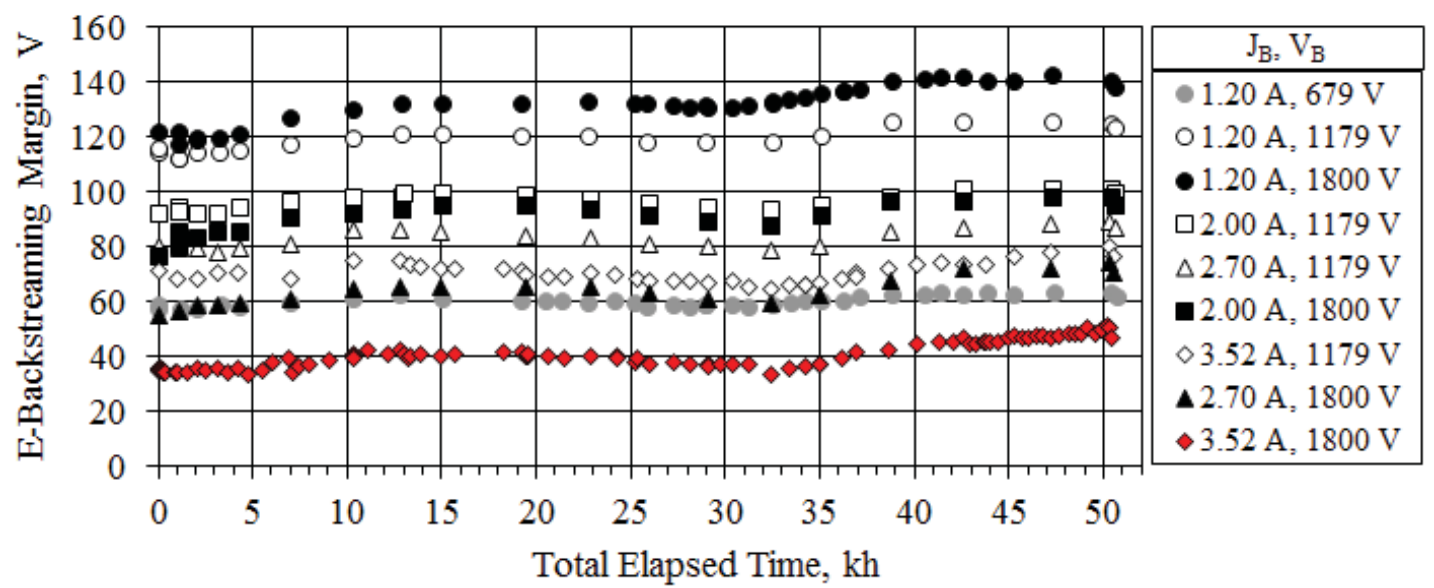

Figure 29. NEXT LDT electron backstreaming margin data as a function of operating time.

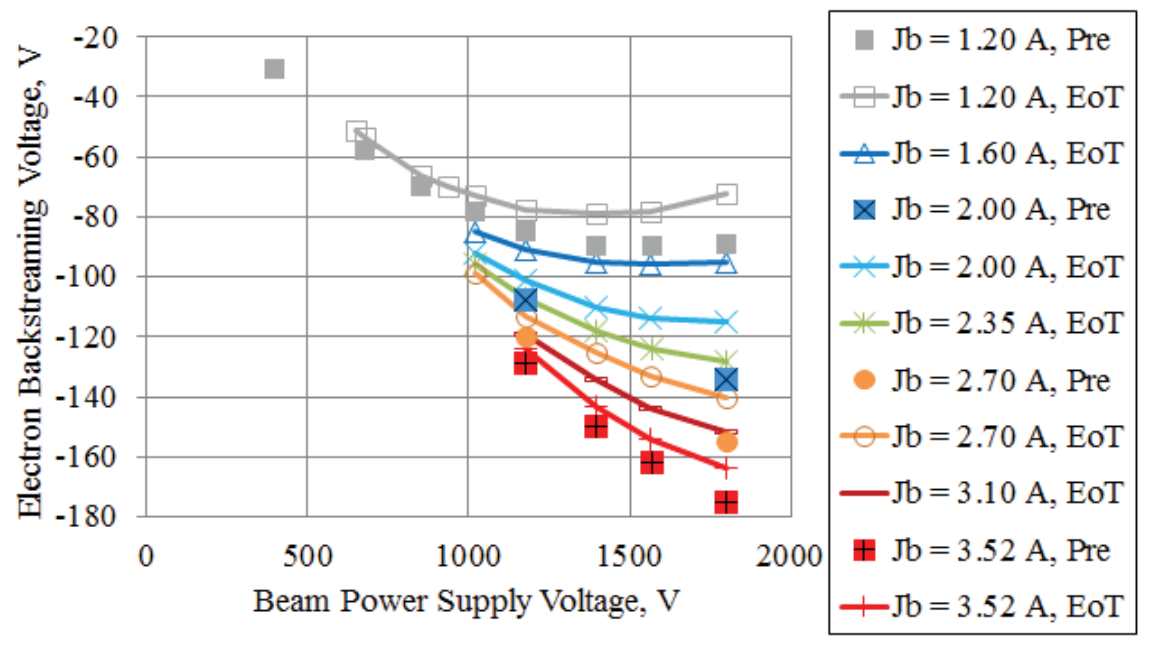

Figure 30. Comparison of electron backstreaming voltage data between pre-test and end-of-test performance characterizations of the NEXT LDT.

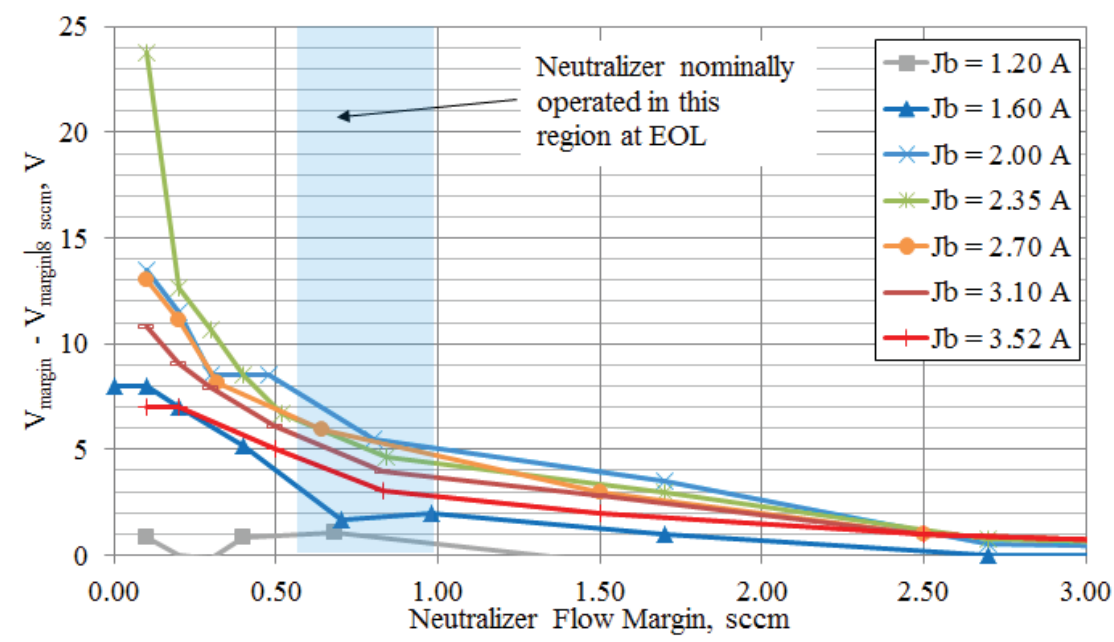

Figure 31. End-of-test characterization of the dependence of electron backstreaming margin on neutralizer flow margin from plume mode. 
Perveance margins increased slightly at the beginning of the test due to chamfering of the downstream edges of the accelerator apertures, similar to that observed during the NSTAR ELT. ${ }^{46}$ These margins have reduced slightly since throttling back to full power at $29.2 \mathrm{kh}$, likely due to backsputtered carbon partially filling in chamfered erosion sites. No changes were observed in the perveance margin as a result of the diagnostic repair. A comparison of the total voltage limit measured during pre-test and end-of-test characterizations is shown in Fig. 33. The total voltage limit is defined as the total grid voltage at which onset of direct beam impingement occurs on the accelerator grid, as defined in Ref. 36. Only modest differences are observed, with a maximum of $50 \mathrm{~V}$ change between pre-test and end-of-test conditions. Screen grid ion transparencies demonstrated a slight decrease over the course of the test, primarily occurring during the two full-power run segments. This decrease of $2-4 \%$ is also readily seen in Fig. 35, which compares the screen grid ion transparency between the pre-test and end-of-test performance characterizations. This trend was originally speculated to be caused by deposits on the screen grid, but preliminary post-test inspection of the hardware showed no evidence of such deposits. The cause of this trend in screen grid ion transparency is therefore still being investigated. Observed changes in electron backstreaming limit, perveance limit, and screen grid ion transparency are not significant enough to degrade the ion optics performance. Also, they are less than or equal to those exhibited by the NSTAR optics during the 8,200 $\mathrm{h}$ wear test and the ELT. ${ }^{35,40}$

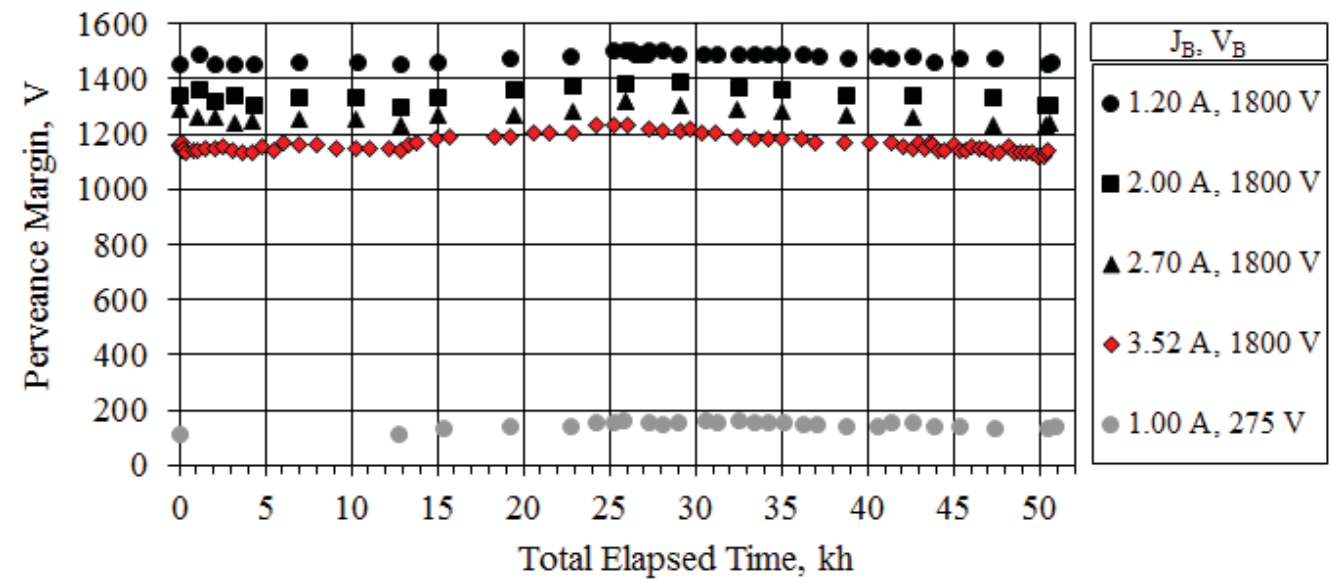

Figure 32. NEXT LDT perveance margin data as a function of operating time.

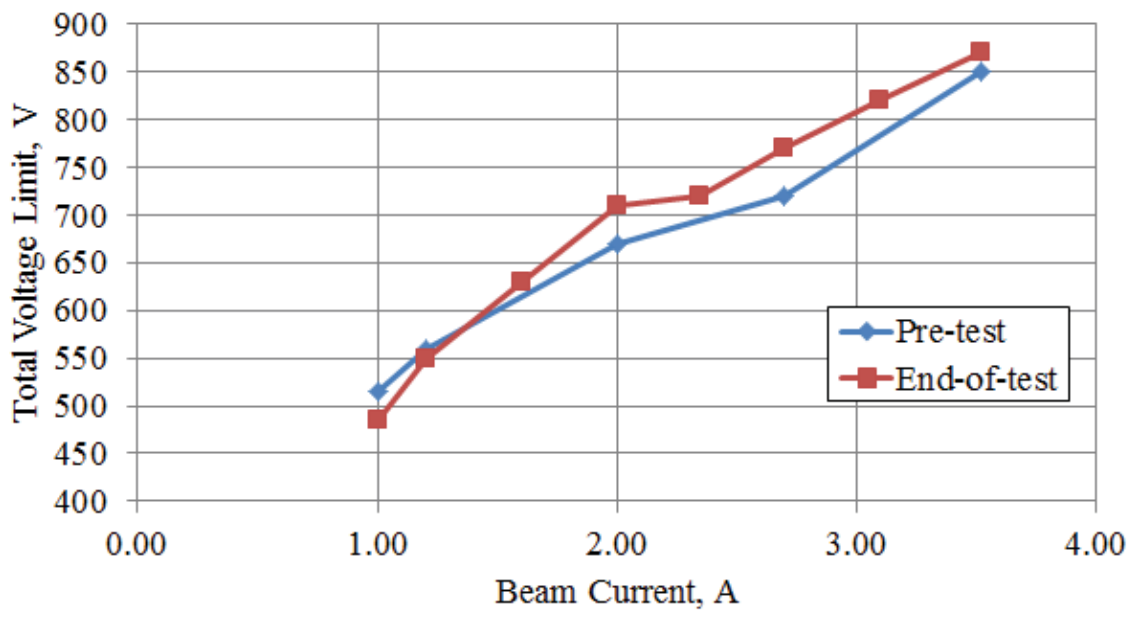

Figure 33. Comparison of the total grid voltage limit between pre-test and end-of-test performance characterizations of the NEXT LDT. 


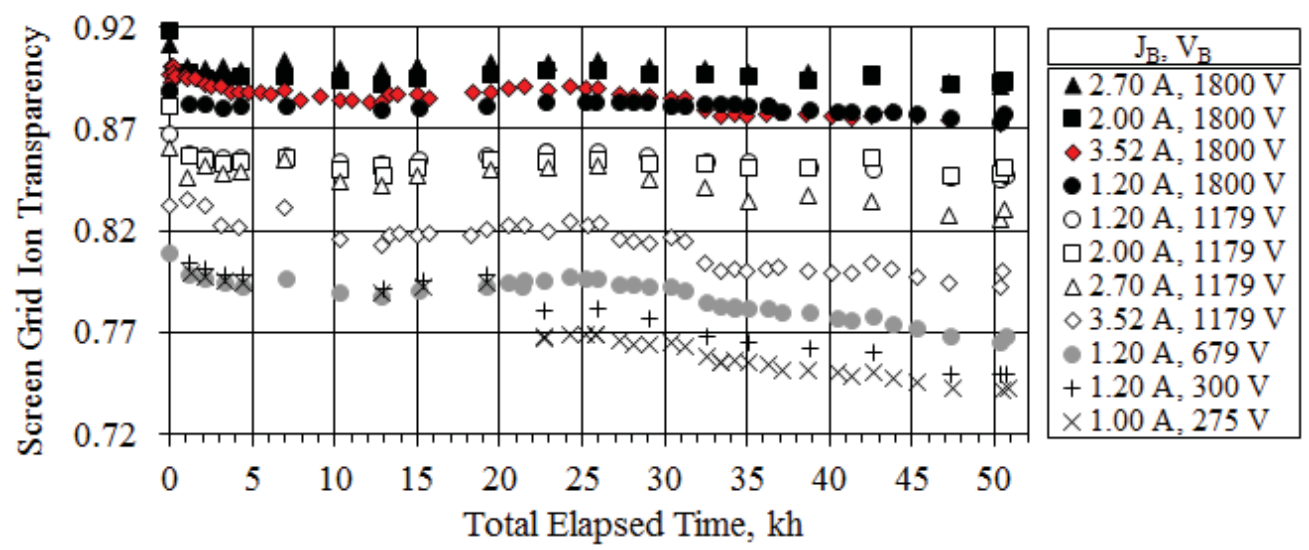

Figure 34. NEXT LDT screen grid transparency as a function of operating time.

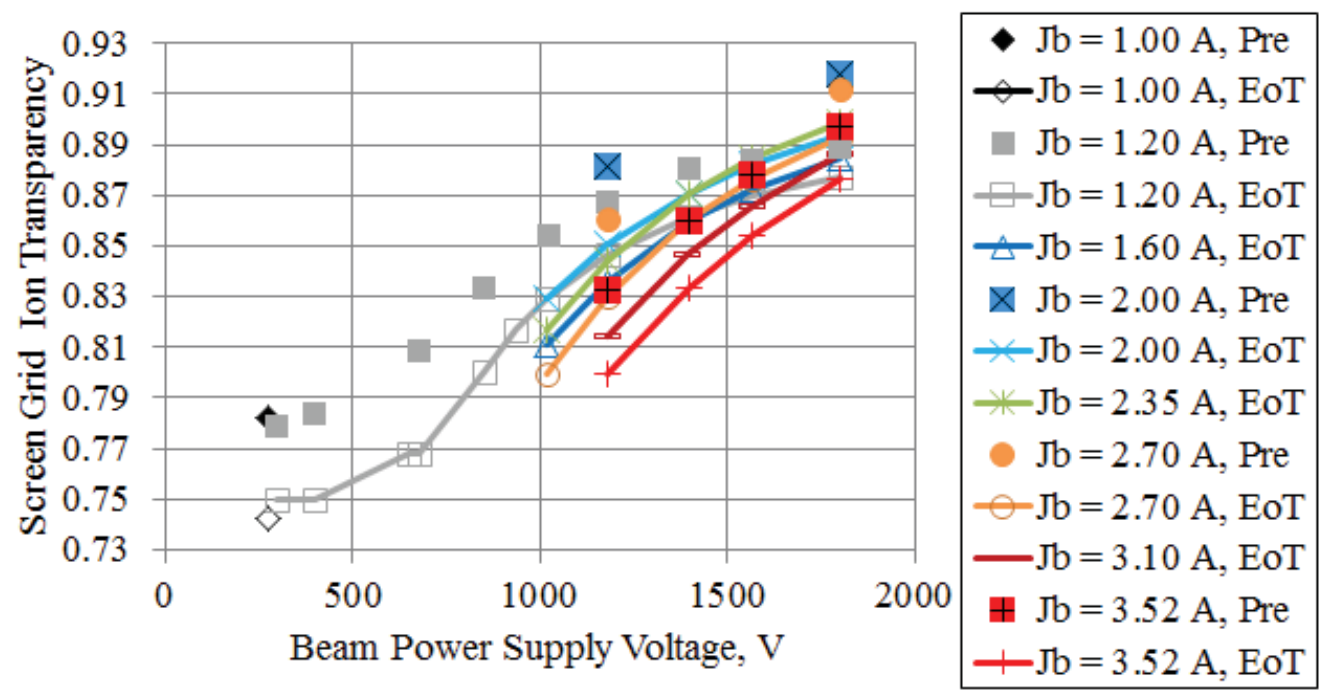

Figure 35. Comparison of screen grid ion transparency data between pre-test and end-of-test performance characterizations of the NEXT LDT.

Figure 36 compares the in-situ camera images of the CRA taken at BOL and at the end of the test after 51,184 hours of operation. Noticeable chamfering of the downstream edge of the aperture as well as pit-and-groove erosion around the aperture is observed. The state of the pit-and-groove pattern in the accelerator grid will be further discussed in Section V. Based on the in-situ images, there is little to no observed change in the aperture cusp diameter. Figure 37 shows the measured cusp diameter, normalized by BOL dimensions, as a function of thruster operating time. Data from the NSTAR ELT is
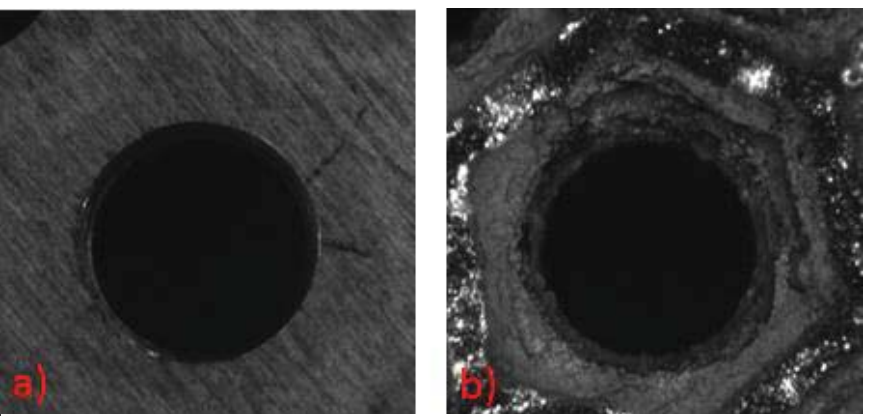

Figure 36. CRA on the accelerator grid for the NEXT LDT taken with in-situ cameras at (a) 0 hours and (b) 51,184 hours. also shown for comparison. The lack of significant barrel erosion was expected based upon the semi-empirical model predictions. ${ }^{18}$ The lack of aperture enlargement is due to the significantly reduced beam current density of NEXT compared to NSTAR, as well as improved manufacturing techniques for the ion optics. Measurements of the CRA aperture diameters taken pre-test and post-test for the NEXT EM1 and PM1R wear tests indicate negligible aperture enlargement as well. ${ }^{19,21,39}$ 


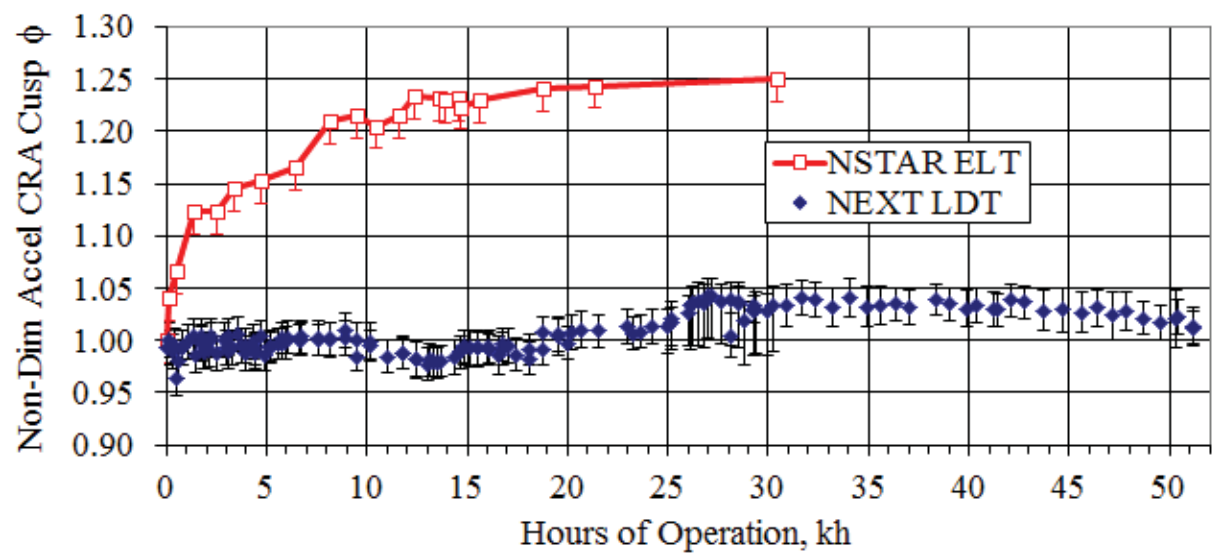

Figure 37. Accelerator grid CRA cusp diameters as a function of operating time for the NEXT LDT and the NSTAR ELT. Values have been normalized by BOL dimensions.

As mentioned previously, the first-failure mode observed during the NSTAR ELT was the inability to prevent electron backstreaming at full power. The elimination of this failure mode for NEXT is primarily attributed to the lower beam current density which results in negligible aperture enlargement. However, a decrease in the ion optics grid gap can cause an increase in electric field between the grids, which can reduce the electron backstreaming margin. Measurements made pre-test and post-test for the NSTAR ELT and 8,200 $\mathrm{h}$ wear test indicated 30\% and $12 \%$ reduction in the cold grid gap, respectively. ${ }^{35,40,46}$ Measurements were not taken during the course of the test; however, electron backstreaming data indicate that the grid gap changed slowly over the duration of the test. ${ }^{46}$ The ion optics assembly and mounting scheme were modified for the NEXT PM design. A set of PM ion optics are included on EM3 for the NEXT LDT. An in-situ camera was placed within VF-16 to measure the cold grid gap over the course of the test. The cold grid gap is expected to trend with any changes in the hot grid gap during operation. Measurements of the cold grid gap, normalized by BOL dimensions, as a function of operating duration are shown in Fig. 38. Measurements from the NSTAR ELT are shown for comparison. The cold grid gap for the NEXT LDT has not changed within the measurement uncertainty. Measurements could not be taken in the period between 36.3 and $50.4 \mathrm{kh}$ due to camera lighting degradation. Restoration of this lighting during the diagnostic repair has allowed confirmation that the cold grid gap has not changed over the course of the test. Improved beam flatness and elimination of a changing grid gap has successfully mitigated the first failure mode encountered in the NSTAR design. These improvements have shifted the first-failure mode to another mechanism that progresses at a much slower rate, resulting in substantial increase in thruster service life capability.

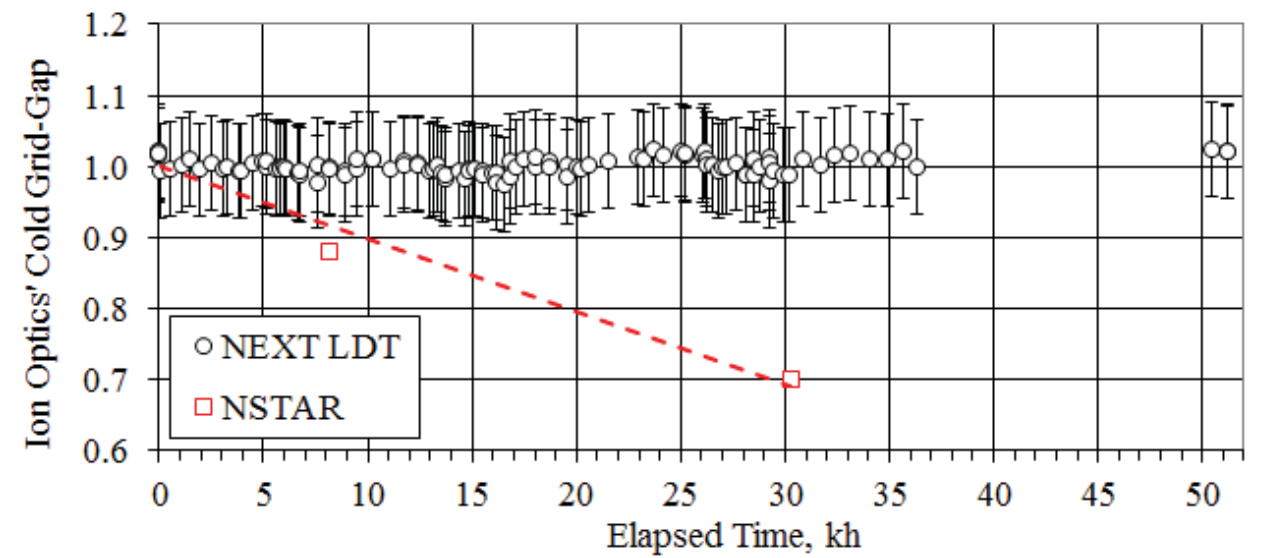

Figure 38. Cold ion optics grid gap as a function of operating time for the NEXT LDT and the NSTAR ELT. Values have been normalized by BOL dimensions. 


\section{NEXT Long Duration Test Results - Status of the First-Failure Mode}

As an evolutionary design, the NEXT thruster has successfully built upon the NSTAR development and flight programs. The LDT has demonstrated that NEXT has mitigated or eliminated many of the wear out modes encountered during the NSTAR development and flight programs. After 30,352 hours of operation, the NSTAR ELT: could no longer operate at full power due to an inability to prevent electron backstreaming; showed complete erosion of the discharge cathode keeper, resulting in exposure of the cathode orifice plate, heater coil, and radiation shield; and charge-exchange ions had penetrated the accelerator grid at the pits in the pit-and-groove erosion pattern.

The NEXT thruster has successfully mitigated many of these issues. At the end of the test, the thruster had accumulated 51,184 hours of operation, could run at every point on the NEXT throttle table, and showed minimal performance degradation. Measurements taken during the LDT have demonstrated negligible changes in CRA cusp diameter and ion optics cold grid gap, resulting in negligible changes in electron backstreaming limit which was predicted by the NEXT service life model. Thus, the first failure mode observed during the NSTAR ELT is not an issue for the NEXT thruster.

The first failure mode for NEXT is predicted to be loss of structural integrity of the ion optics due to penetration of the pit-and-groove structure through the accelerator grid. The accelerator grid groove depth was measured via an optical diagnostic technique as a function of operating duration from $7.6 \mathrm{kh}$ to $35.6 \mathrm{kh}^{47}$ Groove depth measurements could no longer be obtained after 35,618 hours of operation due to in-situ camera lighting degradation as well as shadowing of the groove due to groove depth and lighting angle. Prior to diagnostic repair, a number of techniques were used to indirectly determine if groove penetration had occurred. ${ }^{32}$ None of these techniques indicated such penetration had occurred prior to the diagnostic repair effort.

The diagnostic repair effort took multiple steps to ensure that adequate, on-axis lighting was present to properly measure the groove depth and check for groove penetration, as detailed in Section III. Figure 39 shows the pit-andgroove pattern at the center of the accelerator grid taken with the in-situ camera for grid gap measurement $\left(45^{\circ}\right.$ angle with respect to ion optics) after the diagnostic repair with restored lighting. A photograph of the pattern after extended operation at TL37 (19,520 h of thruster operation) is shown for comparison. A number of features are present in the pit-and-groove pattern at $50.5 \mathrm{kh}$. The pattern appears to be irregular and exhibits variability around a given aperture and also from aperture to aperture. This is in contrast to the pattern that was observed at $19.5 \mathrm{kh}$. While some grooves appear to have high "ridges" of carbon that surround the erosion site, others appear to show evidence of carbon spalling off. Despite the use of adequate lighting, a groove measurement could not be made with any fidelity due to the lack of a proper reference surface. Initial inspection of the accelerator grid after exposure of the thruster to atmosphere did not indicate that the grooves had penetrated through the grid thickness. Lastly, there is evidence from the in-situ images, as well as the preliminary post-test inspection, of carbon deposits within the pitand-groove structure at the center of the accelerator grid.
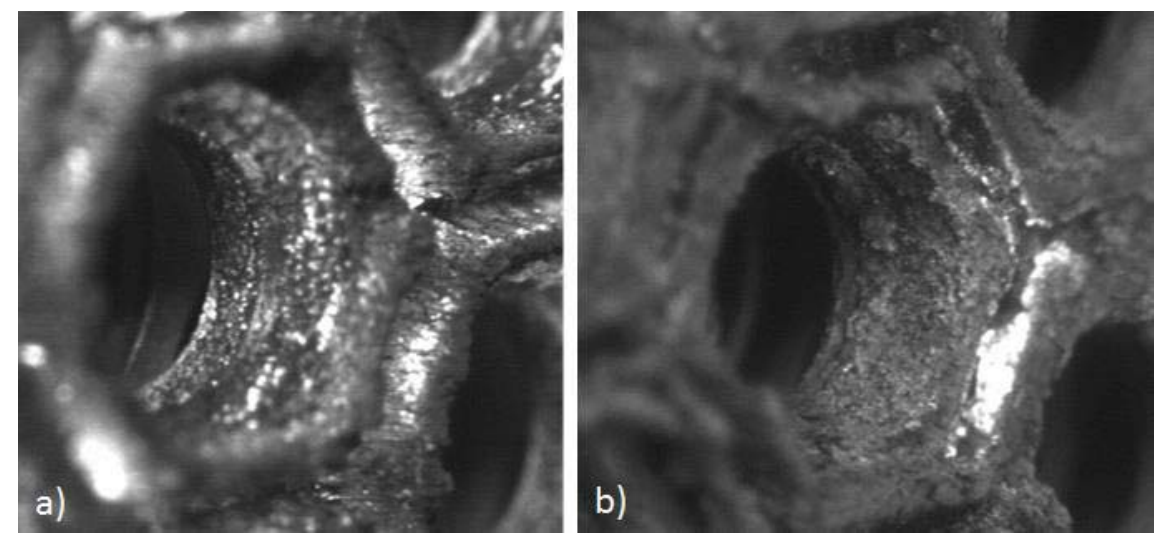

Figure 39. Pit-and-groove pattern at the center of the accelerator grid of the NEXT LDT taken with the in-situ camera after (a) 19,520 $\mathrm{h}$ and (b) 50,453 h.

In an effort to determine when carbon deposition began accumulating within the pit-and-groove pattern, a detailed examination was conducted of images taken outside of the facility during the test. These images indicate that the central area of the accelerator grid began to slowly change appearance around $36 \mathrm{kh}$, corresponding to approximately $600 \mathrm{~kg}$ throughput and $22.5 \mathrm{MN}$-s of total impulse. Loss of adequate lighting for the in-situ cameras that image the grid also occurred around this time. It is possible that carbon buildup within the pit-and-groove pattern is responsible for this change in grid appearance. However, the exact cause of this change in grid appearance 
and in the behavior of the carbon deposition on the grid is still an active area of investigation. QCM measurements indicate that the facility backsputter rate did not significantly change over the course of the test (see Section VI). Also, the three-dimensional nature of the pit-and-groove structure at $50 \mathrm{kh}$ indicates that whatever caused the change in grid appearance and carbon deposition behavior cannot be reproduced by simple 1-D or 2-D models. It is likely that destructive post-test analyses, where the accelerator grid is sectioned, will be required to determine the final depth of the pit-and-groove pattern on the accelerator grid. This measurement will be critical in the investigation to determine the root cause of the carbon deposits within the pit-and-groove structure. These results will then be used in the ongoing assessment of the first failure mode in ground testing.

\section{NEXT Long-Duration Test Results - Backsputter Rates and Facility Backpressure Effects}

As mentioned in Section III, during the diagnostic repair two new crystals were placed within the QCM in order to obtain accurate facility backsputter rates at the thruster location for various operating conditions. Also, an auxiliary flow line was placed mid-length along VF-16 to artificially increase the facility pressure and characterize changes in thruster telemetry. The results of these studies on facility effects are discussed below.

\section{Measured Backsputter Rates}

Prior to QCM failure, backsputter rates were measured primarily during performance testing when dwell times at a given operating condition are a maximum of a few hours. This created a high degree of uncertainty at low-power, low-backsputter operating conditions where film thicknesses would only increase by 5-10 angstroms. It should be noted that a higher-fidelity measurement was taken at full power since the measurement was taken during extended wear testing. In order to obtain a more accurate measurement after the diagnostic repair, QCM data were collected over the course of at least 12 hours for each of the five operating conditions in the LDT throttle profile (where the majority of thruster operating time was spent). This extended duration allowed for a sufficient change in film thickness even at low power conditions. For each of these conditions, measurements were also compared between the gold-plated and aluminum alloy-plated crystals and displayed agreement to within $1 \%$. Linear regression was performed on the measured film thickness as a function of time to obtain the backsputter rate for a given operating condition. Only the results from the gold-plated crystal are reported here.

Table 3 gives the measured facility backsputter rates after diagnostic repair. For comparison, the measured backsputter rates at the beginning of the test for TL40 and TL37 were $2.9 \mu \mathrm{m} / \mathrm{khr}$ and 1.4 $\mu \mathrm{m} / \mathrm{khr}$, respectively. These values are in reasonable agreement with the measured values at $50 \mathrm{kh}$, indicating that the backsputter rate did not Table 3. Measured backsputter rates at $50 \mathrm{kh}$ for the five operating conditions in the LDT throttle profile.

\begin{tabular}{|c|c|c|c|}
\hline $\begin{array}{c}\text { Throttle } \\
\text { Level }\end{array}$ & $\begin{array}{c}\text { Input Power, } \\
\mathrm{kW}\end{array}$ & $\begin{array}{c}\text { Operating Condition } \\
\left(\mathrm{J}_{\mathrm{B}}, \mathrm{V}_{\mathrm{B}}\right)\end{array}$ & $\begin{array}{c}\text { Backsputter Rate, } \\
\mu \mathrm{m} / \mathrm{khr}\end{array}$ \\
\hline \hline TL40 & 6.9 & $3.52 \mathrm{~A}, 1800 \mathrm{~V}$ & 2.8 \\
\hline TL37 & 4.7 & $3.52 \mathrm{~A}, 1179 \mathrm{~V}$ & 1.2 \\
\hline TL05 & 1.1 & $1.20 \mathrm{~A}, 679 \mathrm{~V}$ & 0.2 \\
\hline TL01 & 0.5 & $1.00 \mathrm{~A}, 275 \mathrm{~V}$ & 0.1 \\
\hline TL12 & 2.4 & $1.20 \mathrm{~A}, 1800 \mathrm{~V}$ & 1.0 \\
\hline
\end{tabular}
change significantly throughout the course of the test. Using the backsputter rates from Table 3 and the operating durations for each condition from Table 1 , the calculated total film thickness over the course of the test is $108.5 \mu \mathrm{m}$.

During the diagnostic repair, backsputtered carbon film samples were taken from an exposed facility endcap surface that was grit-blasted prior to initiation of the test. While this surface was located above and behind the thruster at an angle that is not normal to the facility centerline, it was the surface most representative of the thruster location where carbon samples could be extracted. These films were analyzed using scanning electron microscopy. photograph of one of the films is shown in Fig. 40. Based on the image, the estimated film thickness is approximately $87 \mu \mathrm{m}$. The discrepancy between this measured thickness and that calculated from the backsputter rates is likely due to the non-ideal location from where the sample was taken,

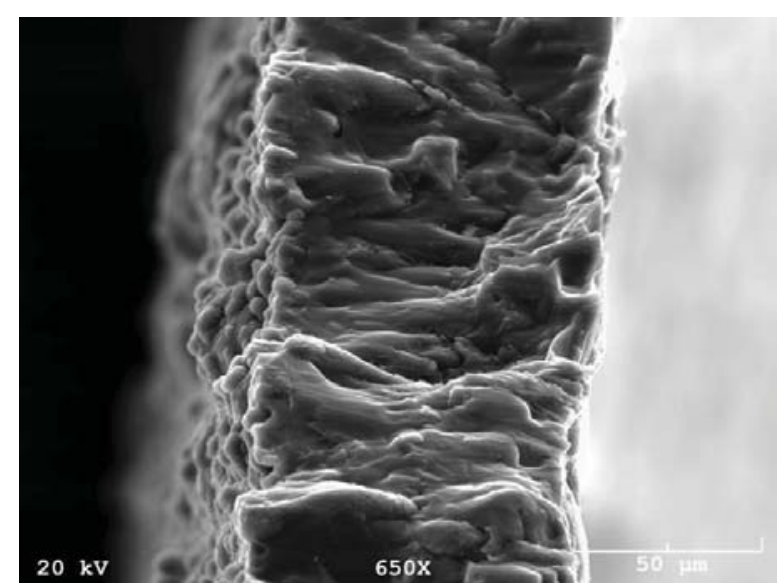

Figure 40. Scanning electron microscopy image of carbon film sample taken from facility endcap during diagnostic repair. 
resulting in partial shadowing by the thruster and a non-normal incidence angle for deposition. Furthermore, the measured backsputter rates assume that the material is entirely made of carbon, while the film likely includes traces of heavier elements. Elemental analyses of these film samples are underway to confirm its composition.

\section{Facility Backpressure Effects}

Thruster telemetry was recorded for the five operating conditions in the LDT throttle profile at various facility pressures ranging from $1 \mathrm{X}$ nominal pressure to $3-4 \mathrm{X}$ nominal pressure. The outlet for the auxiliary flow line was pointed downstream, and facility pressure was measured using a high-accuracy hot-cathode ionization gauge next to the thruster. During the first pressure variation study, beam current was held constant by adjusting the discharge current to account for the increased ingested flow. During the second study, the beam current was held constant by adjusting the main plenum mass flow rate.

The measured accelerator grid current was plotted as a function of facility backpressure (corrected for xenon) for each operating condition. The curve was then extrapolated back to zero-pressure conditions to estimate the accelerator current that would be observed in the space environment (see Fig. 41). This was done to better characterize facility effects on downstream accelerator grid erosion. Due to the slight non-linearity observed at higher facility pressures, the extrapolation was performed in two ways. First, a second-order polynomial was fit to the entire pressure range. Second, a linear function was fit to the lower-pressure data. These two methods yielded extrapolated values in good agreement with one another, with variations not exceeding $12 \%$. Furthermore, the two techniques used to hold beam current constant with pressure also yielded extrapolated values that agreed within 5\%. Therefore, only the second-order polynomial fit to the data where the main plenum mass flow rate was adjusted is presented here. This data set is arguably the most accurate extrapolation to space-like conditions, and also yielded the most conservative (largest) value for accelerator current for most operating conditions. However, the main plenum mass flow rate was not adjusted for TL37 due to the negligible difference observed at TL40 between the two techniques. Therefore, data where the discharge current was adjusted to maintain beam current will be presented for TL37.

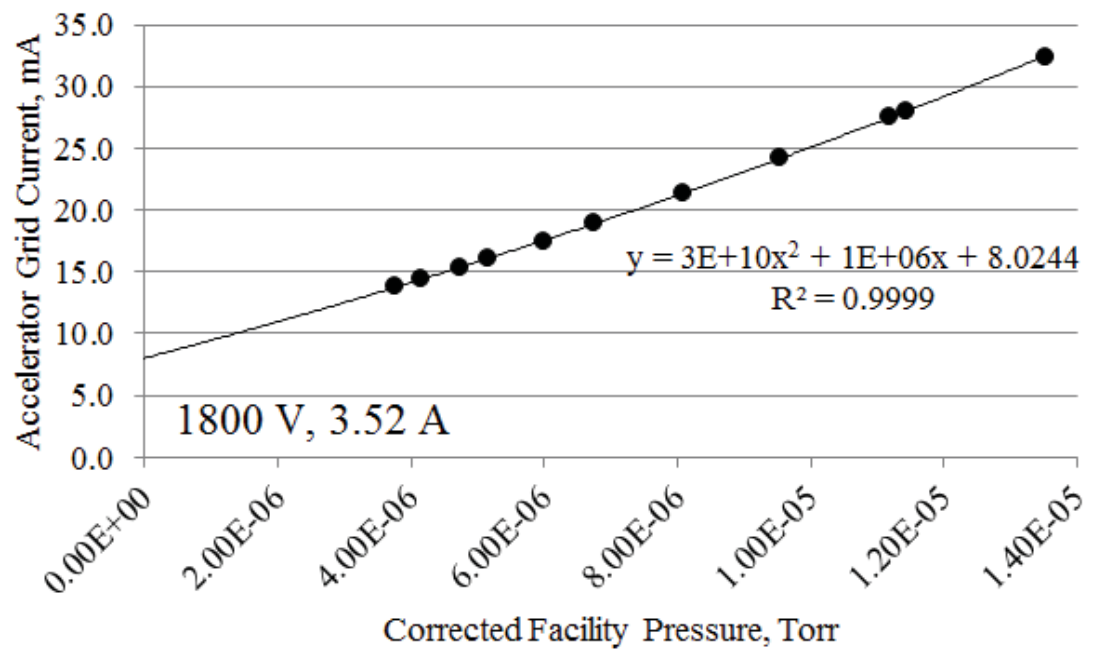

Figure 41. Measured accelerator grid current as a function of facility pressure at full power. Beam current was held constant by adjusting the main plenum mass flow to account for increased neutral ingestion.

Table 4 compares the measured accelerator grid currents at nominal facility pressure to those extrapolated to zero-pressure conditions. Measured currents exceeded zero-pressure currents by $35-75 \%$, with a strong dependence on the beam current (and total mass flow rate). This information is critical when characterizing the overall facility effect on downstream accelerator grid erosion. Furthermore, data in Table 4 indicates that the zero-pressure accelerator current varies from $0.13-0.25 \%$ of the beam current. These values are important when estimating overall performance and lifetime in flight. Modeling will be required to estimate the overall impact these facility effects would have on thruster lifetime. 
Table 4. Comparison of measured accelerator grid currents and extrapolated currents to zero-pressure conditions.

\begin{tabular}{|c|c|c|c|c|}
\hline $\begin{array}{c}\text { Throttle } \\
\text { Level }\end{array}$ & $\begin{array}{c}\text { Operating Condition } \\
\left(\mathrm{J}_{\mathrm{B}}, \mathrm{V}_{\mathrm{B}}\right)\end{array}$ & $\mathrm{J}_{\mathrm{A} \text {, facility }}, \mathrm{mA}$ & $\mathrm{J}_{\mathrm{A}, 0}, \mathrm{~mA}$ & $\mathrm{~J}_{\mathrm{A}, \text { facility }} / \mathrm{J}_{\mathrm{A}, 0}$ \\
\hline \hline TL40 & $3.52 \mathrm{~A}, 1800 \mathrm{~V}$ & 14.0 & 8.0 & 1.75 \\
\hline TL37 & $3.52 \mathrm{~A}, 1179 \mathrm{~V}$ & 14.6 & 8.9 & 1.64 \\
\hline TL05 & $1.20 \mathrm{~A}, 679 \mathrm{~V}$ & 2.4 & 1.6 & 1.50 \\
\hline TL01 & $1.00 \mathrm{~A}, 275 \mathrm{~V}$ & 2.3 & 1.7 & 1.35 \\
\hline TL12 & $1.20 \mathrm{~A}, 1800 \mathrm{~V}$ & 3.9 & 2.6 & 1.50 \\
\hline
\end{tabular}

\section{Conclusions}

The NEXT LDT is the major test component of a comprehensive service life assessment involving a combination of multiple wear tests and analyses. Upon completion of the test in February 2014, the NEXT LDT has accumulated 51,184 hours of operation, processed $918 \mathrm{~kg}$ of xenon, and delivered $35.5 \mathrm{MN}-\mathrm{s}$ of total impulse. The thruster surpassed its original throughput qualification goal of $450 \mathrm{~kg}$ in December 2009, and completed its throttle profile for model validation in May 2010. The NEXT LDT has successfully completed or exceeded all of its goals, and demonstrated that NEXT has mitigated several of the failure modes encountered in the NSTAR design.

After successfully repairing numerous diagnostics within the test facility which had failed over the course of the test, a comprehensive end-of-test performance characterization was made prior to exposing the thruster to atmosphere. These data confirmed many of the trends observed over the course of the test, such as steady performance with minimal degradation, as well as mitigation of several failure modes such as discharge cathode keeper erosion, accelerator aperture enlargement and changing ion optics cold grid gap. Numerous studies were also performed to characterize facility effects, such as facility backsputter rates and elevated backpressure, in order to better predict thruster performance in flight-like conditions. The end-of-test characterization also included studies on how neutralizer performance changes with keeper current, as this will inform how to avoid neutralizer plume mode while maximizing thruster efficiency over the thruster's service life. The first failure mode of NEXT is expected to be loss of structural integrity of the ion optics due to penetration of the pit-and-groove pattern through the accelerator grid. Despite the use of enhanced lighting within the vacuum chamber, no evidence of groove penetration was found at the end of the test. Presently the test article for the NEXT LDT was vented to atmosphere, with post-test disassembly and inspection underway. The post-test analyses will be needed to confirm many of the findings from the NEXT LDT, as well as provide information on the final state of the thruster which will be used to complete the NEXT service life assessment.

\section{Acknowledgments}

The authors would like to thank and acknowledge the NASA Science Mission Directorate's In-Space Propulsion Technology (SMD ISPT) Program for funding this work as well as Todd Peterson and Eric Pencil for serving as the Project Managers. The authors would also like to thank and acknowledge the entire NEXT team at NASA GRC and JPL for their support of the NEXT LDT, valuable input to the test execution, and assistance in interpreting the test data and thruster behavior. Special thanks to Jonathan Van Noord for providing details relating to the NEXT thruster service life assessment for inclusion in this paper and comparison to measured LDT data. Finally, the authors would like to thank the facilities staff for their tremendous effort to maintain vacuum conditions for over eight years continuously through various power, water, and liquid nitrogen outages, hot-swap of the facility programmable logic control, as well as a multitude of other obstacles.

\section{References}

\footnotetext{
${ }^{1}$ Brophy, J. R., et al., "Development and Testing of the Dawn Ion Propulsion System", 42nd AIAA/ASME/SAE/ASEE Joint Propulsion Conference and Exhibit, AIAA-2006-4319, Sacramento, CA, July 9-12, 2006.

${ }^{2}$ Patterson, M. J. and Benson, S. W., "NEXT Ion Propulsion System Development Status and Performance", 43rd AIAA/ASME/SAE/ASEE Joint Propulsion Conference and Exhibit, AIAA-2007-5199, Cincinnati, OH, July 8-11, 2007.

${ }^{3}$ Polk, J. E., et al., "Demonstration of the NSTAR Ion Propulsion System on the Deep Space One Mission", 27th International Electric Propulsion Conference, IEPC-2001-075, Pasadena, CA, October 15-19, 2001.
} 
${ }^{4}$ Rayman, M. D., "The Successful Conclusion of the Deep Space 1 Mission: Important Results Without a Flashy Title", Space Technology, Vol. 23, No. 2-3, 2003, pp. 185-196.

${ }^{5}$ Benson, S. W. and Patterson, M. J., "NASA's Evolutionary Xenon Thruster (NEXT) Ion Propulsion Technology Development Status in 2009", 31st International Electric Propulsion Conference, IEPC-2009-150, Ann Arbor, MI, September 20-24, 2009.

${ }^{6}$ Hoskins, W. A., Aadland, R. S., Meckel, N. J., Talerico, L. A., and Monheiser, J. M., "NEXT Ion Propulsion System Production Readiness", 43rd AIAA/ASME/SAE/ASEE Joint Propulsion Conference and Exhibit, AIAA-2007-5856, Cincinnati, OH, July 8-11, 2007.

${ }^{7}$ Patterson, M. J., et al., "NEXT Multi-Thruster Array Test - Engineering Demonstration", 42nd AIAA/ASME/SAE/ASEE Joint Propulsion Conference and Exhibit, AIAA-2006-5180, Sacramento, CA, July 9-12, 2006.

${ }^{8}$ Snyder, J. S., Anderson, J. R., Van Noord, J. L., and Soulas, G. C., "Environmental Testing of the NEXT PM1 Ion Engine", 43rd AIAA/ASME/SAE/ASEE Joint Propulsion Conference and Exhibit, AIAA-2007-5275, Cincinnati, OH, July 8-11, 2007.

${ }^{9}$ Soulas, G. C., Patterson, M. J., Pinero, L., Herman, D. A., and Snyder, J. S., "NEXT Single String Integration Test Results", 45th AIAA/ASME/SAE/ASEE Joint Propulsion Conference and Exhibit, AIAA-2009-4816, Denver, CO, August 2-5, 2009.

${ }^{10}$ Aadland, R. S., Frederick, H., Benson, S. W., and Malone, S. P., "Development Results of the NEXT Propellant Management System", JANNAF 2nd Liquid Propulsion Subcommittee and 1st Spacecraft Propulsion Subcommittee Joint Meeting, JANNAF 2005-0356DW, Monterey, CA, December 5-8, 2005.

${ }^{11}$ Crofton, M. W., et al., "Characterization of the NASA NEXT Thruster", 45th AIAA/ASME/SAE/ASEE Joint Propulsion Conference and Exhibit, AIAA-2009-4815, Denver, CO, August 2-5, 2009.

${ }^{12}$ Herman, D. A., Pinero, L. R., and Sovey, J. S., "NASA's Evolutionary Xenon Thruster (NEXT) Component Verification Testing", 44th AIAA/ASME/SAE/ASEE Joint Propulsion Conference and Exhibit, AIAA-2008-4812, Hartford, CT, July 21-23, 2008.

${ }^{13}$ Herman, D. A., Soulas, G. C., and Patterson, M. J., "Performance Evaluation of the Prototype-Model NEXT Ion Thruster", 43rd AIAA/ASME/SAE/ASEE Joint Propulsion Conference and Exhibit, AIAA-2007-5212, Cincinnati, OH, July 8-11, 2007.

${ }^{14}$ Pinero, L. R., Hopson, M., Todd, P. C., and Wong, B., "Performance of the NEXT Engineering Model Power Processing Unit", 43rd AIAA/ASME/SAE/ASEE Joint Propulsion Conference and Exhibit, AIAA-2007-5214, Cincinnati, OH, July 8-11, 2007.

${ }^{15}$ Snyder, J. S., et al., "Vibration Test of a Breadboard Gimbal for the NEXT Ion Engine", 42nd AIAA/ASME/SAE/ASEE Joint Propulsion Conference and Exhibit, AIAA-2006-4665, Sacramento, CA, July 9-12, 2006.

${ }^{16}$ Dankanich, J. W., Brophy, J. R., and Polk, J. E., "Lifetime Qualification Standard for Electric Thrusters", 45th AIAA/ASME/SAE/ASEE Joint Propulsion Conference and Exhibit, AIAA-2009-5095, Denver, CO, August 2-5, 2009.

${ }^{17}$ Van Noord, J. L., "Lifetime Assessment of the NEXT Ion Thruster", 43rd AIAA/ASME/SAE/ASEE Joint Propulsion Conference and Exhibit, AIAA-2007-5274, Cincinnati, OH, July 8-11, 2007.

${ }^{18}$ Van Noord, J. L. and Herman, D. A., "Application of the NEXT Ion Thruster Lifetime Assessment to Thruster Throttling", 44th AIAA/ASME/SAE/ASEE Joint Propulsion Conference and Exhibit, AIAA-2008-4526, Hartford, CT, July 21-23, 2008.

${ }^{19}$ Soulas, G. C., Kamhawi, H., Patterson, M. J., Britton, M. A., and Frandina, M. M., "NEXT Ion Engine 2000 Hour Wear Test Results", 40th AIAA/ASME/SAE/ASEE Joint Propulsion Conference and Exhibit, AIAA-2004-3791, Fort Lauderdale, FL, July 11-14, 2004.

${ }^{20}$ Soulas, G. C. and Patterson, M. J., "NEXT Ion Thruster Performance Dispersion Analyses", 43rd AIAA/ASME/SAE/ASEE Joint Propulsion Conference and Exhibit, AIAA-2007-5213, Cincinnati, OH, July 8-11, 2007.

${ }^{21}$ Van Noord, J. L., Soulas, G. C., and Sovey, J. S., "NEXT PM1R Ion Thruster and Propellant Management System Wear Test Results", 31st International Electric Propulsion Conference, IEPC-2009-163, Ann Arbor, MI, September 20-24, 2009.

${ }^{22}$ Hoskins, W. A., et al., "Development of a Prototype Model Ion Thruster for the NEXT System", 40th AIAA/ASME/SAE/ASEE Joint Propulsion Conference and Exhibit, AIAA-2004-4111, Fort Lauderdale, FL, July 11-14, 2004.

${ }^{23}$ Frandina, M. M., Arrington, L. A., Soulas, G. C., Hickman, T. A., and Patterson, M. J., "Status of the NEXT Ion Thruster Long Duration Test", 41st AIAA/ASME/SAE/ASEE Joint Propulsion Conference and Exhibit, AIAA-2005-4065, Tucson, AZ, July 10-13, 2005.

${ }^{24}$ Herman, D. A., Soulas, G. C., and Patterson, M. J., "Performance Characteristics of the NEXT Long-Duration Test after 16,550 $\mathrm{h}$ and $337 \mathrm{~kg}$ of Xenon Processed", 44th AIAA/ASME/SAE/ASEE Joint Propulsion Conference and Exhibit, AIAA-20084527, Hartford, CT, July 21-23, 2008.

${ }^{25}$ Herman, D. A., Soulas, G. C., and Patterson, M. J., "NEXT Long-Duration Test Plume and Wear Characteristics after 16,550 h of Operation and $337 \mathrm{~kg}$ of Xenon Processed", 44th AIAA/ASME/SAE/ASEE Joint Propulsion Conference and Exhibit, AIAA-2008-4919, Hartford, CT, July 21-23, 2008.

${ }^{26}$ Patterson, M. J., et al., "NEXT: NASA's Evolutionary Xenon Thruster", 38th AIAA/ASME/SAE/ASEE Joint Propulsion Conference and Exhibit, AIAA-2002-3832, Indianapolis, IN, July 7-10, 2002.

${ }^{27}$ Soulas, G. C., Domonkos, M. T., and Patterson, M. J., "Performance Evaluation of the NEXT Ion Engine", 39th AIAA/ASME/SAE/ASEE Joint Propulsion Conference and Exhibit, AIAA-2003-5278, Huntsville, AL, July 20-23, 2003.

${ }^{28}$ Herman, D. A., Soulas, G. C., and Patterson, M. J., "Status of the NEXT Long-Duration Test after 23,300 Hours of Operation", 45th AIAA/ASME/SAE/ASEE Joint Propulsion Conference and Exhibit, AIAA-2009-4917, Denver, CO, August 2-5, 2009. 
${ }^{29}$ Herman, D. A., "Status of the NASA's Evolutionary Xenon Thruster (NEXT) Long-Duration Test after 30,352 Hours of Operation", 46th AIAA/ASME/SAE/ASEE Joint Propulsion Conference and Exhibit, AIAA-2010-7112, Nashville, TN, July 25 $28,2010$.

${ }^{30}$ Herman, D. A., "NASA's Evolutionary Xenon Thruster (NEXT) Project Qualification Propellant Throughput Milestone: Performance, Erosion, and Thruster Service Life Prediction after $450 \mathrm{~kg}$ ", JANNAF 7th Modeling and Simulation, 5th Liquid Propulsion, and 4th Spacecraft Propulsion Joint Subcommittee Meeting, CPIAC JSC 2010-0015EH and NASA TM-2010216816, Colorado Springs, CO, May 3-7, 2010.

${ }^{31}$ Herman, D. A., Soulas, G. C., and Patterson, M. J., "NEXT Long-Duration Test Neutralizer Performance and Erosion Characteristics", 31st International Electric Propulsion Conference, IEPC-2009-154, Ann Arbor, MI, September 20-24, 2009.

${ }^{32}$ Shastry, R., Herman, D. A., Soulas, G. C., and Patterson, M. J., "Status of NASA's Evolutionary Xenon Thruster (NEXT) Long-Duration Test as of 50,000 h and $900 \mathrm{~kg}$ Throughput", 33rd International Electric Propulsion Conference, IEPC-2013-121, Washington D.C., October 6 - 10, 2013.

${ }^{33}$ Soulas, G. C., "Design and Performance of $40 \mathrm{~cm}$ Ion Optics", 27th International Electric Propulsion Conference, IEPC01-090, Pasadena, CA, October 15-19, 2001.

${ }^{34}$ Patterson, M. J., Haag, T. W., and Hovan, S. A., "Performance of the NASA $30 \mathrm{~cm}$ Ion Thruster", 23rd International Electric Propulsion Conference, IEPC-93-108, Seattle, WA, September 13-16, 1993.

${ }^{35}$ Sengupta, A., et al., "An Overview of the Results from the 30,000 Hr Life Test of Deep Space 1 Flight Spare Ion Engine", 40th AIAA/ASME/SAE/ASEE Joint Propulsion Conference and Exhibit, AIAA-2004-3608, Fort Lauderdale, FL, July 11-14, 2004.

${ }^{36}$ Soulas, G. C., Foster, J. E., and Patterson, M. J., "Performance of Titanium Optics on a NASA $30 \mathrm{~cm}$ Ion Thruster", $36 t h$ AIAA/ASME/SAE/ASEE Joint Propulsion Conference and Exhibit, AIAA-2000-3814, Huntsville, AL, July 16-19, 2000.

${ }^{37}$ Soulas, G. C., "Performance Evaluation of Titanium Ion Optics for the NASA $30 \mathrm{~cm}$ Ion Thruster", 27th International Electric Propulsion Conference, IEPC-01-092, Pasadena, CA, October 15-19, 2001.

${ }^{38}$ Sengupta, A., Brophy, J. R., and Goodfellow, K. D., "Status of the Extended Life Test of the Deep Space 1 Flight Spare Ion Engine After 30,352 Hours of Operation", 39th AIAA/ASME/SAE/ASEE Joint Propulsion Conference and Exhibit, AIAA-20034558, Huntsville, AL, July 20-23, 2003.

${ }^{39}$ Kamhawi, H., Soulas, G. C., Patterson, M. J., and Frandina, M. M., "NEXT Ion Engine 2000 hour Wear Test Plume and Erosion Results", 40th AIAA/ASME/SAE/ASEE Joint Propulsion Conference and Exhibit, AIAA-2004-3792, Fort Lauderdale, FL, July 11-14, 2004.

${ }^{40}$ Polk, J. E., et al., "An Overview of the Results from an 8200 Hour Wear Test of the NSTAR Ion Thruster", 35th AIAA/ASME/SAE/ASEE Joint Propulsion Conference and Exhibit, AIAA-1999-2446, Los Angeles, CA, June 20-24, 1999.

${ }^{41}$ Doerner, R. P., Whyte, D. G., and Goebel, D. M., "Sputtering Yield Measurements during Low Energy Xenon Plasma Bombardment", Journal of Applied Physics, Vol. 93, No. 9, May 1, 2003, pp. 5816-5823.

${ }^{42}$ Doerner, R. P. and Goebel, D. M., "Sputtering Yields of Ion Thruster Grid and Cathode Materials During Very Low Energy Xenon Plasma Bombardment", 39th AIAA/ASME/SAE/ASEE Joint Propulsion Conference and Exhibit, AIAA-2003-4561, Huntsville, AL, July 20-23, 2003.

${ }^{43}$ Williams, G. J., et al., "Results of the $2000 \mathrm{hr}$ Wear Test of the HiPEP Ion Thruster with Pyrolytic Graphite Ion Optics", 42nd AIAA/ASME/SAE/ASEE Joint Propulsion Conference and Exhibit, AIAA-2006-4668, Sacramento, CA, July 9-12, 2006.

${ }^{44}$ Britton, M., Soulas, G. C., Kamhawi, H., and Snyder, A., Destructive Analysis of the NEXT 2000-Hour Wear Test Hollow Cathode Assemblies. 2005, NASA Glenn Research Center: Cleveland, OH.

${ }^{45}$ Mikellides, I. G., Snyder, J. S., Goebel, D. M., Katz, I., and Herman, D. A., "Neutralizer Hollow Cathode Simulations and Comparisons with Ground Test Data", 31st International Electric Propulsion Conference, IEPC-2009-20, Ann Arbor, MI, September 20-24, 2009.

${ }^{46}$ Sengupta, A., et al., The 30,000-Hour Extended-Life Test of the Deep Space 1 Flight Spare Ion Thruster. 2005, The Jet Propulsion Laboratory and NASA Glenn Research Center: Pasadena.

${ }^{47}$ Herman, D. A., "Review of the NASA's Evolutionary Xenon Thruster (NEXT) Long-Duration Test as of $632 \mathrm{~kg}$ of Propellant Throughput", 47th AIAA/ASME/SAE/ASEE Joint Propulsion Conference and Exhibit, AIAA-2011-5658, San Diego, CA, July 31 - August 3, 2011. 